San Jose State University

SJSU ScholarWorks

Master's Theses

Master's Theses and Graduate Research

1989

\title{
Effects of public health nursing intervention on the self-esteem of pregnant and parenting teenage mothers
}

Joyce Brown

San Jose State University

Follow this and additional works at: https://scholarworks.sjsu.edu/etd_theses

\section{Recommended Citation}

Brown, Joyce, "Effects of public health nursing intervention on the self-esteem of pregnant and parenting teenage mothers" (1989). Master's Theses. 3126.

DOI: https://doi.org/10.31979/etd.fu5r-94vn

https://scholarworks.sjsu.edu/etd_theses/3126

This Thesis is brought to you for free and open access by the Master's Theses and Graduate Research at SJSU ScholarWorks. It has been accepted for inclusion in Master's Theses by an authorized administrator of SJSU ScholarWorks. For more information, please contact scholarworks@sjsu.edu. 


\section{INFORMATION TO USERS}

The most advanced technology has been used to photograph and reproduce this manuscript from the microfilm master. UMI films the text directly from the original or copy submitted. Thus, some thesis and dissertation copies are in typewriter face, while others may be from any type of computer printer.

The quality of this reproduction is dependent upon the quality of the copy submitted. Broken or indistinct print, colored or poor quality illustrations and photographs, print bleedthrough, substandard margins, and improper alignment can adversely affect reproduction.

In the unlikely event that the author did not send UMI a complete manuscript and there are missing pages, these will be noted. Also, if unauthorized copyright material had to be removed, a note will indicate the deletion.

Oversize materials (e.g., maps, drawings, charts) are reproduced by sectioning the original, beginning at the upper left-hand corner and continuing from left to right in equal sections with small overlaps. Each original is also photographed in one exposure and is included in reduced form at the back of the book. These are also available as one exposure on a standard $35 \mathrm{~mm}$ slide or as a $17^{\prime \prime} \times 23^{\prime \prime}$ black and white photographic print for an additional charge.

Photographs included in the original manuscript have been reproduced xerographically in this copy. Higher quality $6^{\prime \prime} \times 9^{\prime \prime}$ black and white photographic prints are available for any photographs or illustrations appearing in this copy for an additional charge. Contact UMI directly to order.

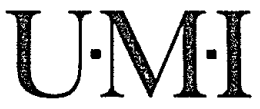


. 
Order Number 1938679

Effects of public health nursing intervention on the self-esteem of pregnant and parenting teenage mothers

Brown, Joyce M., M.S.

Smith, Kim, M.S.

Uchishiba, Alene, M.S.

San Jose State University, 1989

Copyright (C1990 by Brown, Joyce M., Smith, Kim, and Uchishiba, Alene. All rights reserved.

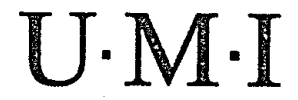

300 N. Zeeb Rd.

Ann Arbor, MI 48106 



\title{
EFEECTS OF PUBLIC HEALTH NURSING INTERVENTION \\ ON THE \\ SELF-ESTEEM OF PREGNANT AND \\ PARENTING TEENAGE MOTHERS
}

\author{
A Thesis \\ Presented to \\ The Faculty of the Department of Nursing \\ San Jose State University
}

In Partial Fulfillment

of the Requirements for the Degree

Master of Science

\author{
BY \\ Joyce Brown \\ Kim Smith \\ Alene Uchishiba \\ August 1989
}


APPROVED FOR THE DEPARTMENT OF NURSING $\frac{\text { Mary Geeve }}{\text { Mary Reve, R.N., M.S., Ed.D. }}$

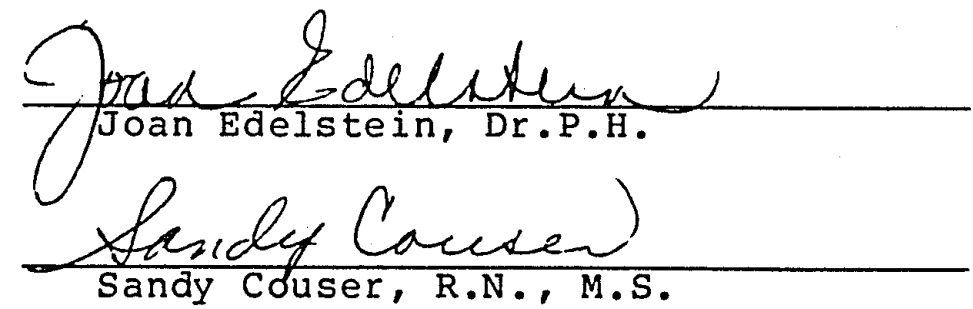

\section{APPROVED FOR THE UNIVERSITY}

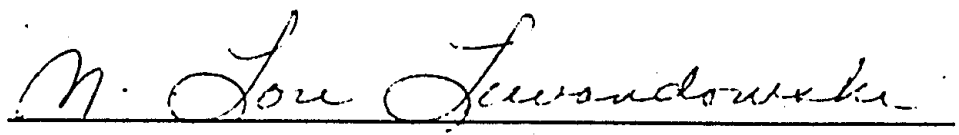




\begin{abstract}
The purpose of this pilot study was to evaluate the effect of public health nursing interventions on the self-esteem of pregnant and parenting teenagers in Monterey County. The study was conducted from June, 1988 to February, 1989. Participants were given a Coopersmith SEI pre- and post-test and a questionnaire was used to gather demographic data. T-tests were utilized to compare mean scores of pre-and post-tests. Demographic data showed important information. A large majority were Hispanic, half of the school age participants were abused, half were children of teenage mothers, and a majority had siblings who were teenage parents. A fourth of all participants were substance abusers. Although the self-esteem of adolescents in this study was not significantly affected by public health nurse intervention, the sample size of 25 was too small to determine all but the most obvious differences.
\end{abstract}




\title{
ACKNOWLEDGMENTS
}

\author{
To our families who have supported us \\ through this process.
}

To Monterey County Health Department for allowing us to utilize public health nurses and clients for the study.

To Barbara S. Brown, Director of Public Health Nursing, for her idea and support for this thesis.

To Clara Keller, librarian at Natividad Medical Center, for her expertise in assisting us with the literature search.

To Connie Flynn for her time and talents as our volunteer editor, typist and computer consultant.

To Mary Reeve, R.N., M.S., Ed.D., our first reader, for her patience and continued support.

To Supervisor Barbara Shipnuck, for her wisdom, concern and dedication to health concerns. 
TABLE OF CONTENTS

Page

LIST OF TABLES . . . . . . . . . . . . vii LIST OF FIGURES . . . . . . . . . . . . viii Chapter

1. INTRODUCTION ............... I 1 Statement of the Problem ....... 3 Hypothesis . . . . . . . . . . 4 Purpose and Need........... 5 Definition of Terms . . . . . . 7 Research Design . . . . . . . . 8 Scope and Limitations . . . . . . 8

2. CONCEPTUAL FRAMEWORK AND REVIEW OF RELATED LITERATURE . . . . . . . . 10 Conceptual Framework . . . . . . . 10 Related Literature.......... 14

3. THE METHOD .............. 18 Research Design .......... 18 Data Collection ........... 21

4. ANALYSIS AND INTERPRETATION OF DATA • • . 24 Description of the Sample . . . . . . 24 Analysis Regarding Complications . . . . 24

5. CONCLUSIONS AND RECOMMENDATIONS . . . . 29 Conclusions .......... 2. 29 Recommendations ......... 32 
Page

REFERENCES . . . . . . . . . . . . . . . . 42

APPENDICES

A. Participant Consent Letter . . . . 47

B. Introductory Letter . . . . . . . 50

C. Questionnaire for Demographic

Information . . . . . . . 52

D. Permission Letter for Use of Tool . . 55

E. Coopersmith SEI . . . . . . . 57

F. Monterey County Health Department

Trap Forms . . . . . . . . 60 


\section{LIST OF TABLES}

Table

Page

1. Demographic Statistical Values for

Adult Age Participants. . . . . . . 34

2. Demographic statistical Values for

School Age Participants . . . . . . 35

3. Cumulative statistical values for

Adult Age Participants. . . . . . 36

4. Cumulative statistical Values for

School Age Participants . . . . . . 37

5. Raw Data Scores of Pre- and Post-Tests . . 38 


\section{LIST OF FIGURES}

Figure

Page

1. Raw Scores of Pre- and Post-Tests for

School Age Participants . . . . . . 39

2. Raw Scores of Pre- and Post-Tests for

Adult Age Participants. . . . . . . 40 


\section{Chapter I}

INTRODUCTION

Adolescent pregnancy and parenthood are increasingly common today and pose many problems for the individual persons involved as well as society as a whole. The period of adolescence is a step in the process of life's adjustment towards adult status. According to Flick (1986), the happenings during this period of the individual's development have been predetermined by previous experiences and began with the moment of birth and continues throughout childhood.

It appears that girls enter puberty (as indicated by the physical sexual changes) with lower self-esteem than boys and consistently report more negative responses to these events. Pubertal events are but one of multiple simultaneous transitions that act in concert to affect self-esteem (Orr, Wilbrandt, Brach, Rauch, \& Ingersoll, 1989, p. 89).

Patten (1981) found that groups of pregnant teens had lower self-concepts when compared to norms of the general population. "Pregnant adolescents reported more dissatisfaction with family relationships and physical selves, greater feelings of inadequacy and unworthiness, and lower self-esteem than did nonpregnant adolescents" (Patten, 1981, p. 770). 
According to Meisenhelder (1985), pediatric texts consider self-esteem a key developmental process and an important stimulant for nurturing and responsive mothering behavior. Zuravin (1988) states that studies agree that independent of socioeconomic status teenage mothers: (a) are less responsive and sensitive to their infants than older mothers, (b) have less desirable child-rearing attitudes and expectations, and (c) do provide more adequate care when supported socially and emotionally by family members. Nursing has long recognized self-esteem as an essential element in an individual's mental and physical health. "Disturbance in self-concept, a classification category for self-esteem, is an officially accepted nursing diagnosis, and standard nursing textbooks routinely include self-esteem when laying their foundation for a holistic nursing focus" (Meisenhelder, 1985, p. 127). Therefore, health care settings which promote intensive client contact maximize the nurses' influence on their clients' self-esteem. Such settings allow the nurse to establish long-term bonds with the client, to build up trust over time, and to establish credibility. Public health nursing has a long tradition of providing long-term close contacts that seek to promote and maintain health and well-being, therefore increasi.ng the clients' self-esteem. 
Statement of the Problem

"Overall, the goal of nursing is to help people meet needs or adapt to stressors, as movement is made through developmental stages, and to regain homeostasis at any point on the health-illness continuum" (Wyatt \& Omar, 1985, p. 169). During a time when teenagers are examining and questioning morals and values, teenage pregnancy presents a complex phenomenon that not only taxes government and social resources, but gravely affects the future of the teenagers themselves, as well as their children and families. "Adolescent pregnancy is the major cause of females dropping out of high school" (Senate office of Research, 1984, p. 5.).

The health risks facing adolescent mothers, particularly those under 15 years of age, include a greater risk of death and chances of developing nonfatal maternal complications such as anemias, pregnancy induced hypertension, caesarean delivery for cephalopelvic disproportion, and depression. Prematurity, congenital problems, delayed development, and child abuse and neglect are health problems for the infants of teenage parents. The social consequences include increased school dropout ratès, poor employment status, increased poverty, and family disintegration. 
These factors indicate that an adequate response to teenage pregnancy is imperative and must include more than providing medical services to the mother and child. Investigations into the self-esteem of pregnant and parenting teenagers may show something about why teenage females become pregnant.

This information is important because: (a) teenage pregnancy remains at an epidemic level and has been associated with serious negative medical, social, economic and educational effects on the continued development of the adolescent female, (b) nurses can make incense efforts to understand and provide the most effective health care to that segment of the population, (c) nursing interventions, such as counseling and anticipatory guidance can be used more effectively (Pass, 1986, p. 248).

Hypothesis

"For the nurse, educator, and researcher alike, the evaluation of self-esteem is an initial step toward betier understanding human motivation" (Gilberts, 1983, p. 29). Through an understanding of how self-esteem may vary, specific public health nursing interventions targeted at increasing positive self-esteem might be envisioned. Public health nursing interventions in the areas of teaching, guidance, and support targeted at pregnant and 
parenting teenagers might influence positive health behaviors, role functions, and coping capacity.

This study hypothesized that pregnant and parenting teenage mothers who experience public health nurse interventions have an increased self-esteem. For the purpose of this study, the researchers identified the independent variable to be public health nursing intervention and the dependent variable to be client self-esteem.

\section{Purpose and Need}

The purpose of this study was to measure the effect of public health nursing interventions on the self-esteem of pregnant teenagers and teenage mothers. The question statement for this study was: What is the effect of public health nursing interventions in the areas of teaching and support on the self-esteem of pregnant and parenting teenage mothers?

Teenagers whose needs are not satisfied adequately may search for closeness, caring, bonding, and love. These teenagers may crave to be touched, held, and cared for by others, and may meet these needs through sexual relationships. Pregnancy may result from these relationships and may meet the need for unconditional love. Patten (1981) reported that the forces contributing to pregnancy in adolescence were chaotic early life experiences which led to poor structuring of the ego and 
super-ego deficits. Patten (1981) concluded that weak ego strength resulted in sexual acting out and pregnancy. "The symbolic importance of motherhood as a passage into adult status and the intervening effects of normative group anchorage may mediate between individual cognitive ability and their level of self-esteem" (Streetman, 1987, p. 459). The American culture makes transition from adolescence to adulthood extremely difficult because of confusion of values. The adolescent typically looks to the peer group for support, for a set of rules to guide behavior, and the peers become arbiters of appropriate behavior. Dramatic mood swings and intense preoccupation with self and one's fantasies are characteristic. Adolescence is a period of seeming contradictions. Teenagers want to make their own decisions, yet fear growing up and losing the emotional and material support provided by the older generation. During this time of turbulence, adolescents are strongly oriented to the present, which makes planning for the future difficult.

Horn (1987) indicates that pregnancy and the birth of an infant to a teenage mother present a set of unique problems to the young mother, father, infant, their parents, and society as a whole. The researchers theorize that by focusing on nursing interventions and on increasing self-esteem in the pregnant and parenting teenager, the 
indirect effect would be to prevent repeat pregnancy and improve mothering skills.

\author{
Definition of Terms \\ 1. "Self-esteem is a concept pertaining to a
} fundamental sense of efficacy and a fundamental sense of worth, to competence and worthiness in principle" (Branden, 1987, p. 110)

2. Coopersmith Self-Esteem Inventory (SEI) is a tool of self-attitudes. There are two different instruments. One is a 25 item paper-pencil instrument for teenagers over 16 years of age and the other is a 58 item paper-pencil instrument for teenagers 15 and under.

3. Coopersmith Adult Age Form is the test to be used for participants 16 years or older.

4. Coopersmith School Age Form is the test to be used for participants 15 years or younger. This tool measures self-esteem in four areas. The areas measured are social self-peers, home-parents, school academic, and general self.

5. Public Health Nurse (PHN) is a registered nurse who has graduated from a National League for Nursing (NLN) accredited program and provides health promotion and disease prevention services to clients. This applies to employees employed by Monterey County Health Department.

6. Adolescents Caring for Themselves (ACT) is a program established by the Monterey County Board of 
Supervisors in Monterey County in 1987 for the prevention of teenage pregnancies.

7. Taught, Referred, Assessment, Progress Notes (TRAP) model is a tool formulated by Monterey County Health Department public health nurses to record nursing interventions in a standardized and simplified manner.

Research Design

A quasi-experimental study was used because randomization was not possible and there was no control group. Pre- and post-tests utilizing the Coopersmith SEI tool were administered to a group of 25 pregnant and parenting teenagers in a non-random fashion. Participation was on a voluntary basis. Interventions consisting of guidance, teaching, and support were done by public health nurses based on agency policies for follow-up of pregnant teenagers and teenage mothers.

\section{Scope and Limitations}

The study was Iimited to 25 pregnant and parenting teenage mothers in Monterey County. Because the independent variable was public health nursing intervention, and the dependent variable was self-esteem, additional difficulties may have emerged when aspects of the self are estimated by self-report. Potential sources of error in self-reporting include social desirability, need for approval, and concept development. Gilberts (1983) refers to the tendency for people to provide 
information about themselves that they perceive to be socially desirable rather than disclose their true thoughts and feelings. There also may have been limitations in the responses due to language, cultural, and social backgrounds of some of the participants.

The large numbers of nurses performing the interventions and variations of teaching styles may have affected the outcome. Lack of cooperation by the public health nurses gathering the data, as well as passive-resistive behavior patterns may have affected the outcome. Behaviors such as not encouraging enrollment and failure to provide enough interventions during the study period decreased the number of clients parcicipating in the study. 


\section{Chapter 2}

\section{CONCEPTUAL FRAMEWORK AND REVIEW OF RELATED LITERATURE}

Conceptual Framework

The conceptual frameworks for this study was drawn from Maslow (1968), Mercer (1979), and Orem (1985). Maslow places love before esteem in his hierarchy of needs. Maslow (1968) stated that individuals mature and achieve a level of self-actualization only if environmental conditions enable certain basic needs be met first. Maslow (1968) stressed that individuals first strive to meet their physiological survival needs, then their need for love and belonging, self-esteem needs, and finally their desire to obtain knowledge to know and understand. Maslow's conceptual framework was chosen for this study because Maslow advocated an environment that would permit individuals to sequentially meet these needs and actualize their own potential. "As basic needs are fulfilled, the individual becomes naturally motivated to meet more advanced needs" (Wilson \& Kneisl, 1983, p. 247).

According to Reasoner (1983) who based his article on Maslow's hierarchy of needs, research on self-esteem and motivation should focus on the development of five basic attitudes: a sense of security, a sense of identity or self-concept, a sense of belonging, a sense of purpose, and a sense of personal competence. "By fostering the 
environmental conditions conducive to each of these attitudes in a sequential fashion, adolescents are able to grow in their feelings of self-confidence, personal competence, and independence" (Reasoner, 1983, p. 55).

In addition to hierarchal levels, tasks of adolescence have been postulated as milestones in the process of reaching adulthood. Mercer (1979) identified six tasks that, together with consideration of Maslow's levels of self-actualization, provide a useful framework for selecting appropriate pregnancy interventions: "acceptance and comfort with body image; determination and internalization of sexual identity and role; development of a personal value system; preparation for productive citizenship; achievement of independence from parents; and development of an adult identity" (p. 406). All the developmental tasks have implications for sexual activity, contraceptive behavior, and child-bearing.

With the above conceptual frameworks as a foundation, the researchers turned to nursing's role related to helping the pregnant and parenting teenager assume responsibility for her own self-care.

The theory of self-care guides nurses in the calculation of their client's therapeutic self-care in designing systems of nursing or dependent care to ensure that self-care requisites will be met, and in performing or guiding actions through which the 
components of the care demands are met (Orem, 1985, p. 103).

Orem labels her self-care deficit theory of nursing as a general theory. This general theory is composed of three related theories: (1) the theory of self-care, which describes and explains self-care; (2) the theory of self-care deficit, which describes and explains why people can be helped through nursing; (3) the theory of nursing systems, which describes and explains relationships that must be brought about and maintained for nursing to be produced (Marriner, 1986, p. 119).

According to Orem (1985), the theory of self-care expresses the view that human beings are persons who have attained some degree of self-possession. "Within the theory of self-care, person and environment are identified as unity characterized by human-environmental interchanges and by the impact of one upon the other" (Orem, 1985, p. 1021 .

Along with self-care comes the nursing challenge of assisting clients to comply with their therapeutic self-care demand. In this study, the therapeutic self-care demand is to increase self-esteem in the pregnant and parenting teenage mother in order that she may become more responsible for her own self-care. 
The range of self-care deficits that pregnant and parenciris teenage mothers possess is in the areas of lack of knowledge, lack of skills, lack of motivation, and problems in completion of developmental tasks. This study utilized public health nurse interventions to improve self-care agency by effecting an increase in self-esteem. It was assumed that this intervention would enable the pregnant and parenting teenage mother to more effectively parent her child, as well as to complete in a more positive manner her own developmental tasks.

In nursing situations involving adolescents, the teenager continues in a dependent role which must be guided by a responsible adult. The adolescent lacks effective self-care capacity owing to a lack of knowledge, skill, motivation, or a combination of the three.

Self-care deficits are associated not only with individuals' Iimitations for performing care measures, but also a lack of validity or effectiveness of the self-care in which they engage... with guidance and support from interested and accepting adults, self-care deficits will be improved (Orem, 1985 , p. 130$)$.

Nursing has a responsibility to assist clients in reaching higher levels of self-care. According to Joseph (1980), self-care concepts operate within the framework of the nursing process. 
The steps of the nursing process consist of determining why a person needs nursing (assessment), designing a system of nursing assistance (analysis of data), planning for delivery of the specified nursing assistance (plan), and providing and controlling the delivery of nursing assistance (implementation and evaluation) (Orem, 1985, p. 148).

According to Fenner (1979), Orem's supportive and educative systems of nursing are those in which the client demonstrates a high degree of self-care but still requires nursing to assist or support in the process. Fenner (1979) further states that clients within this category generally require assistance with decision-making, behavior control, and the acquisition of knowledge.

Orem's theory of nursing is considered to be an appropriate conceptual framework for this study. The researchers determined that Orem's theory of self-care will increase self-worth and confidence by promoting independence, knowledge and behavior control.

\section{Related Literature}

Although the literature contained studies concerning self-esteem and pregnant adolescents, there was no evidence of research specific to public health nursing intervention on pregnant and parenting teenage mother's self-esteem. The literature did, however, provide baseline information pertinent to this study. 
Mercer's (1985) research focuses on the community problem of teenage pregnancy as reported by nurse researchers in the areas of prevention, reproduction, decision making, prenatal care, intrapartal outcome, family relationship, and mothering. Mercer (1985) concludes that nurse researchers should focus more on the nursing role in the areas of care for pregnant teenagers because nurses do provide many unrecognized and undocumented services to pregnant teenagers.

There were research articles specific to teenage self-esteem and pregnancy. The study by Vernon, Green, and Frothingham (1983) states that low self-esteem did not increase the risk of teenage pregnancy. This finding was in conflict with studies which documented the link between low self-esteem and teenagers who became pregnant (Protinsky, Sporakowski, \& Atkins, 1982, p. 73; Lineberger, 1987, p. 179; Held, 1981, p. 905; Streetman, 1987, p. 459; Patten, 1981, p. 765). In addition, Giblin (1988) states "that present review of the assessment of self-esteem and locus of control applied to adolescent health studies suggests a modest or insignificant association of these measures of self-concept to health conditions and behaviors" (p. 9). According to streetman's (1987) article on the contrasts in the self-esteem of unwed mothers, the link between emerging sexuality and self-esteem has been related to confidence in self-survival, permissiveness, 
societal norms, parental control, role transitions, urban/rural setting, the symbolic significance of motherhood and increasing age and academic skills. Zuravin (1988) studied the relationship between self-esteem and mothering skills of parenting teenagers.

Social support is probably one of the most important mediating common denominators in the intricate sequence from teenage first births to child maltreatment. This sequence is the frequent consequence of such antecedents as low self-esteem, unemployment, single parenthood and an unmanageable number of children (zuravin, 1988, p. 92). Generally speaking, studies agree that independent of socioeconomic status, teenage mothers are less responsive and sensitive to their infants than older mothers, have less desirable child-rearing attitudes and expectations, and do provide more adequate care when supported socially and emotionally by significant others. "High self-esteem was positively associated with the adolescents receiving emotional and supportive assistance from her mother and significant others" (Giblin, Poland, \& Sachs, 1987, p. 278). Another study by Koniak-Griffin (1988) states that the best predictors of prenatal attachment in adolescents have been found to include planning of pregnancy, intent to keep the infant, and the presence of a network of individuals providing strong social support. 
There were three research articles regarding nursing intervention. Two were public health nursing interventions, but neither dealt with the issue of self-esteem as it relates to pregnant and parenting teenagers. Cox and Wachs (1985) was the only study that addressed public health nurse interventions. According to Cox and wachs (1985), major roles of public health nurses are to identify individuals and aggregates at risk for decreased health and well-being, and to develop both individual and community-based interventions that will maintain and promote health. With the current wave of interest among health providers toward prevention of disease and self maintenance care, client participation becomes essential. Cox and Wachs (1985) also indicated the need to consider developing specific interventions that may be directed at altering a client's motivation for lifestyle changes or for adherence to a prescribed regime. 


\section{Chapter 3}

METHOD

Research Design

A quasi-experimental study was utilized because randomization was not possible and there was no control group. Referrals to ACT and Monterey County Public Health Nursing Branch were received from hospitals, physicians, community agencies, parents, teachers, and the clients themselves. From these referrals, thirty-six volunteer participants agreed to participate in this study. Of the 36 who completed the pre-tests, 25 post-tests were completed.

The Coopersmith Self-esteem Inventory tool was utilized to measure the dependent variable. "Since its development, the SEI has been administered to tens of thousands of children and adults participating in research studies or in special educational or clinical programs to enhance self-esteem" (Coopersmith, 1987, p. 12). "All socioeconomic ranges and many ethnic and cultural groups are represented" (Coopersmith, 1987, p. 12). The SEI is designed to measure evaluative attitudes toward the self in social, academic, family, and personal areas of experience. SEI items are short statements (such as, "I'm a lot of fun to be with") and are answered "like me" or "unlike me." 
There were two different forms utilized to assess self-esteem, depending upon the age of the teenager.

The School Form was used with students aged eight through 15 and consists of 58 items: 50 self-esteem items and eight items that constitute the Lie scale, which is a measure of a student's defensiveness or response as expected. The self-esteem items yield a total score and, if desired, separate scores for four subscales: General Self, Social, Self-Peers, Home-Parents, and School-Academic. The subscales allow for variances in perceptions of self-esteem in different areas of experience.

The Adult Form consisting of 25 items was used with persons aged sixteen and above.

This form was adopted from the school short Form for use with persons over fifteen years of age. The language and situations referred to in the items were modified to make them more meaningful to persons whose lives are not as closely bound to parents and school as are children's. The tests are brief and easily scored. They are reliable and stable (Coopersmith, $1987, \mathrm{p}, 6)$.

Spatz and Johnston (1973) administered the SEI to over 600 students in grades 5,9 , and 12 in a rural school district. From each grade, 100 inventories were selected, and Kuder-Richardson reliability estimates 
(KR20s) were calculated. Obtained coefficients were .81 for grade $5, .86$ for grade 9 , and .80 for grade 12. The coefficients indicate adequate internal consistency for students in all three grades (Coopersmith, 1987, p. 12). According to Coopersmith, a study of SEI construct validity was reported by Kokenes $(1974,1978)$. Her investigations included over 7,600 school children in grades 4 through 8 and were designed to observe the comparative importance of the home, peers, and school to the global self-esteem of preadolescents and adolescents. Her study "confirmed the construct validity of the subscales proposed by Coopersmith as measuring sources of self-esteem" (Coopersmith, 1987, p. 13).

On the basis of studies conducted or reviewed by Coopersmith, it was found that SEI scores are significantly related to creativity, academic achievement, resistance to group pressures, willingness to express unpopular opinions, perceptual constancy, perceived reciprocal liking, perceived popularity, general and test anxiety, selection of difficult tasks, effective communication between parents and youth, and family adjustment (Coopersmith, 1987, p. 13). 
The setting took place in Monterey County which consists of rural, agricultural, and urban areas with a population of 341,000 people. The ethnic backgrounds are varied due to the existence of a military base, migratory workers, and immigrant populations. Based on statistical analysis done by Monterey County Health Department in 1986, there were 459 births to teen mothers in the county, with three target areas (East Salinas, South County, and Marina/Seaside) identified as having the highest number of live births to teenagers. There were 250 births in East Salinas, 70 births in South County, and 93 births in Marina/Seaside. The ethnic backgrounds represented in the three cluster areas were predominantly Hispanic at 249 births, Black at 37 births, Caucasian at 152 births, and 21 in all other ethnic groups.

For this study, the sample population consisted of 36 volunteer participants 18 years of age and under from the three cluster areas of the county. Participants were selected from the ACT program and the Monterey County Health Department public health nursing referrals if they were pregnant teenagers, new teenage parents, and willing to participate in the study. The duration of the study was from June, 1988 to February, 1989.

Data Collection

Data were collected for this study using several different tools. These tools included: (a) consent form 
(Appendix A) with introductory letter (Appendix B), (b) a researcher-designed demographic tool (Appendix C), (c) the Coopersmith SEI tool (Appendix E), (d) Monterey County Health Department TRAP forms (Appendix F).

New referrals on pregnant and parenting teenagers were received by public health nurses. The public health nurse made the initial visit with the client. On the initial visit, the study was discussed and if the client agreed to participate, an introductory letter was given, consent forms were signed, and the pre-test was given. Demographic information was collected by the public health nurses during contacts with the client.

Four to seven interventions were made to establish trust, offer guidance, teach and support, and promote mothering and self-care. These interventions were administered during the antepartum period on some clients, and up to six weeks post-partum on other clients. Depending on the public health nurse's assessment of client needs, the interventions were aimed at improving family relations, self-image and self-care, and mothering skills. Referrals and assistance to access services such as mental health; social services; physicians; Women, Infants and Children's Nutritional Program; family planning; and schools were made. All of the above interventions were made based on the TRAP model (Appendix F). 
According to Meisenhelder (1985), theoretical and empirical sources all predict reflected appraisals of significant others as the major influence on self-esteem. "The people who are significant others are those with high contact, intimate long-term relationships, most likely living with the individual. People who reinforce the individual are more likely to influence self-esteem than those who criticize" (Meisenhelder, 1985, p. 131). The close, intimate contact by the public health nurses with the clients in the study were aimed at establishing the public health nurse as a significant other. Establishing the nurse as a significant other and offering the client guidance, teaching and support should increase self-worth, independence, promote positive parenting skills, and decrease repeat pregnancy. 


\section{Chapter 4}

\section{ANALYSIS AND INTERPRETATION OF DATA}

Description of the Sample

Originally, the researchers proposed to enroll 50 participants in the study. In reality, the researchers were able to enroll 36 participants. Of the 36 volunteer participants who were given pre-tests, 25 participants met the criteria for administration of post-tests. Two of the participants moved out of the area, two refused to take the post-test, and seven had not received enough interventions to qualify for the administration of the post-test. This accounted for a $69 \%$ completion rate. Analysis Regarding Complications

of the 25 participants who met the criterion for completion of the pre- and post-tests; 13 were administered adult pre- and post-tests; eight were administered school pre- and post-tests; four, due to maturation, were administered the school pre-test and the adult post-test. When the two different types of tests were administered to the four participants, the data could not be used for comparison (S. Dibble, Personal Communication, February 20, 1989).

A total of 21 school and adult pre-and post-tests were utilized for comparison in this study. The mean age for school age test participants was 15.083 years with a 
standard deviation of 1.084. The mean age for the adult age test participant was 16.615 years with a standard deviation of 0.768 (Tables 1 and 2). The mean pre-test score for the school age participant was 68.333 with a standard deviation of 12.441 (Table 4). According to Coopersmith (1987), means for school age participants have generally been in the $r$ ange of 70 to 80 with a standard deviation of 11 to 13 (p. 8). The mean pre-test score for adult Ige participants was 67.077 with a standard deviation of 23.161 (T'able 3). Coopersmith (1987) reported in a study of 226 adult age test participants in Northern California that the mean score was 66.7 and the standard deviation was 19.2. There were two adult age participants whose pre-test scores were very low at 12 and 40 , which skewed the standard deviation for the adult group (Table 3).

The mean post-test score for school age participants was 66.000 with a standard deviation of 23.397 (Table 4). Two students scored very 10 at 24 and 42 , skewing the standard deviation (Table 4). The mean post-test score for adult age participants was 67.385 with a standard deviation of 21.716 (Table 3).

Triola (1983) states t-tests are utilized to compare means for small samples. No significant changes in the self-esteem of the participants after public health nurse 
interventions were found (Tables 3 and 4 ) (S. Dibble, Personal Communication, March 5, 1989).

The t-test value of -0.368 for pre- and post-tests of school age participants indicated no significant change in self-esteem after public health nurse intervention (Table 4). The t-test value of 0.059 for pre- and post-tests of adult age participants indicated no significant change in the self-esteem of the participants after public health nurse intervention (Table 3 ).

Analysis of the demographic information for school age participants $(\mathrm{N}=12)$ indicates:

1. Two were in the first trimester of pregnancy when entered into study. Two were in the second trimester. One was in the third trimester. Seven were in the post-partum period.

2. Ten were Hispanic and two Caucasian.

3. Seven were single and living with their birth family; four were living with their partners; and one was married.

4. Five were oldest children.

5. Six had a history of abuse (emotional, physical, and/or sexual).

6. Three had a history of substance abuse.

7. Four had siblings who were teenage parents.

8. Five had mothers who were teenage parents. 
9. Four had received services from a protective Services social worker.

10. Two had chronic physical problems.

11. Eleven were enrolled in a federal nutrition program for Women, Infants and Children.

Demographic information for the adult age participants $(N=13)$ indicates:

1. One entered the study in the first trimester. One entered in the second trimester. Three entered in the third trimester. Eight entered in the post-partum period.

2. One was Black; three were Caucasian; nine were Hispanic; and none were Asian.

3. Eight were single and living with their birth family; five were married and living with their partners.

4. Five were oldest children.

5. Three had a history of abuse (physical, emotional, and/or sexual).

6. Three had a history of substance abuse.

7. One had siblings who were teenage parents.

8. Three had mothers who were teenage parents.

9. Three had received services from a Protective Services social worker.

10. One had chronic physical problems. 
11. Ten were enrolled in a federal nutrition program for Women, Infants and Children. 


\section{Chapter 5}

\section{CONCLUSION AND RECOMMENDATIONS}

Conclusions

The overall question to be answered by this pilot study was: Is there an increase in the self-esteem of pregnant and parenting teenagers after public health nursing interventions? The mean pre- and post-test scores indicate that there were no significant changes in the self-esteem of the participants for this study after public health nurse interventions.

Hormonal shifts, postpartum depression, and the stress of being a new parent may have affected test scores. Other environmental factors such as physical, emotional, and sexual abuse may have influenced test results. Variables affecting internal validity such as history, maturation, instrumentation, and mortality may have affected the results of the study.

The findings addressed in the analysis section indicating a history of psychosocial factors such as abuse, role modeling, and family patterns of teenage pregnancy could greatly assist public health nurses in targeting at-risk clients for early and intensive teaching and supportive interventions. Possibly teenagers evaluate self-esteem more from peers and significant others rather than from health care workers. 
A significant factor in regard to maturation was that four of the participants were given school age pre-tests and adult age post-tests because of a change in age. Coopersmith (1987) guidelines state that participants is years and under be administered the school age tests, and participants 16 years and above be administered the adult age test. The researchers were unable to utilize this data for comparison because the pre-test data was not consistent with the post-test data.

A different type of assessment tool may have been more appropriate for this study because coopersmith guidelines state that a different tool be utilized for different age groups. The population in this study ranged from 13 to 18 years of age necessitating that the researchers utilize two different tools. This factor may have affected the internal validity of the study.

Factors influencing mortality were: two out of 36 participants moved out of the county after having taken the pre-test and prior to taking the post-test; 2) two of the participants refused to take the post-test; and 3) seven did not receive the four to seven nursing interventions required for completing the post-tests. The lack of post-tests meant that the researchers were unable to utilize these data. 
The researchers experienced passive resistance behavior from public health nurses who failed to enroll enough clients and to perform the four to seven interventions. Factors such as increased workload and lack of vested interest by the public health nurses may have resulted in obtaining a less than true representation of the teenage population in Monterey County. The researchers were unable to administer the tests themselves because the agency already had in place public health nurses assigned to the target population. This would have meant a cuplication of services, necessitated a lengthy study period, and would not have fit in the agency structure or protocols. Staff changes in the ACT program may have contributed to the researchers' inability to obtain a larger sample.

According to countywide demographics of the three cluster areas mentioned earlier in the paper, 249 out of 459 (548) were Hispanic. Our study indicates ten out of twelve $(838)$ of the school age participants and nine out of thirteen (698) of the adult age participants in the study were Hispanic. This possibly indicates an over representation of this ethnic group and an under represeniation of the Black and Caucasian groups. The nurse who has the highest percentage of Black and Caucasian teenagers in her caseload failed to submit data representative of this population. 
Staff changes in the ACT program may have contributed to the researchers' inability to obtain a larger sample. Recommendations

In this study, the researchers found that attempting to measure self-esteem in the pregnant and parenting teenager was too vague and too broad. It is recommended that future studies limit measuring the area of self-esteem to a particular category such as school, home, social-self, and peers.

Furthermore, the selection of the population should be limited to a particular trimester, antepartum or post-partum period. Post-tests should be limited to the period of either pregnancy or six months after delivery. This would decrease variables such as hormonal changes, post-partum depression, and taking on the new role of parenting which greatly influences internal validity. By focusing on more specific areas of self-esteem that evaluate home environment and peer relationships, public health nurses might be able to more effectively plan interventions that target prevention of pregnancy.

Testing a larger group, formulating a tool that measures self-esteem for adolescents of all ages, and performing more long-term, high contact interventions may provide more significant data. The study could be repeated using a different tool. If there were no significant changes noted, the interventions should be evaluated for 
content appropriateness of materials and standardization of teaching styles.

To better measure parenting skills, a longitudinal study during the first year of life would provide more accurate data. Specific tools that assess parenting skills and risk factors for child abuse and neglect would provide nurses with data to improve anticipatory guidance and teaching.

The researchers could more closely monitor public health nurse caseloads in an attempt to increase the numbers and obtain a more equitable representation of ethnicity. In order to more closely control variables, the researchers could perform the tests and interventions themselves.

Evaluation of self-esteem is not a simple task. "Building self-esteem can be seen as the process of first establishing a sense of security, a sense of identity, and a sense of belonging" (Reasoner, 1983, p. 63). According to Reasoner (1983), when children feel secure and accepted, they can be encolraged to set goals for themselves. Public health nurses can help pregnant and parenting teenagers accomplish goals that are important to them by encouraging the trenager to develop a sense of personal competence, independent functioning, and increased self-esteem. 
Table 1

Demographic Statistical Values for Adult Age Participants (N $\equiv$ 13)

\begin{tabular}{ccc}
\hline Demographics & Mean & $\begin{array}{l}\text { Standard } \\
\text { Deviation }\end{array}$ \\
\hline Age & 16.615 & 0.768 \\
Grade & 10.000 & 0.816 \\
\hline
\end{tabular}


Table 2

Demographic statistical Values for School Age Participants (N $\equiv 12)$

\begin{tabular}{crc}
\hline Demographics & Mean & $\begin{array}{l}\text { Standard } \\
\text { Deviation }\end{array}$ \\
\hline Age & $\begin{aligned} 15.083 \\
8.917\end{aligned}$ & $\begin{array}{l}1.084 \\
1.311\end{array}$ \\
\hline
\end{tabular}


Table 3

Cumulative statistical Values for Adult Age Participants $\underline{(N} \equiv \underline{13)}$

\begin{tabular}{llll}
\hline & Mean & $\begin{array}{l}\text { Standard } \\
\text { Deviation }\end{array}$ & T-Value \\
\hline Total (Pre-Test) & 67.077 & 23.161 & \\
Total (Post-Test) & 67.385 & 21.716 & 0.059 \\
\hline
\end{tabular}


Table 4

Cumulative Statistical Values for School Age Participants $\underline{(\mathrm{N}} \equiv$ 12)

\begin{tabular}{lrrr} 
& Mean & $\begin{array}{l}\text { Standard } \\
\text { Deviation }\end{array}$ & T-Value \\
\hline Total (Pre-Tests) & 68.333 & 12.441 & \\
General & 18.000 & 4.306 & \\
Social & 5.667 & 1.775 & \\
Home & 5.500 & 2.153 & \\
School & 5.000 & 1.537 & \\
Lie & 3.083 & 1.782 & \\
& & & \\
Total (Post-Tests) & 66.000 & 23.397 & -0.368 \\
General & 18.125 & 6.334 & -0.319 \\
Social & 5.500 & 1.690 & -0.552 \\
Home & 4.875 & 2.357 & -1.256 \\
School & 4.500 & 2.390 & -0.935 \\
Lie & 2.750 & 1.488 & 0.000 \\
& & & \\
\hline
\end{tabular}




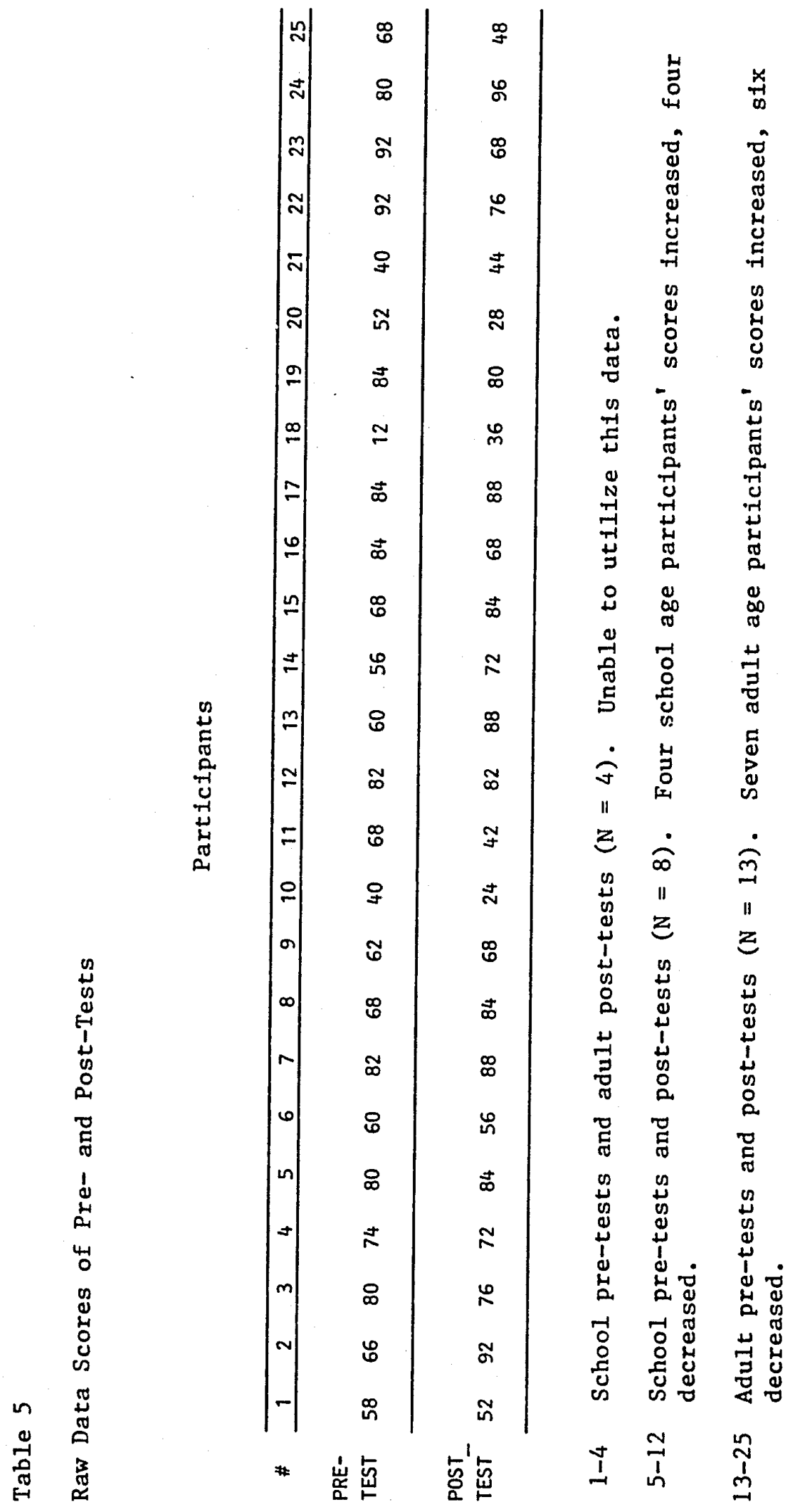




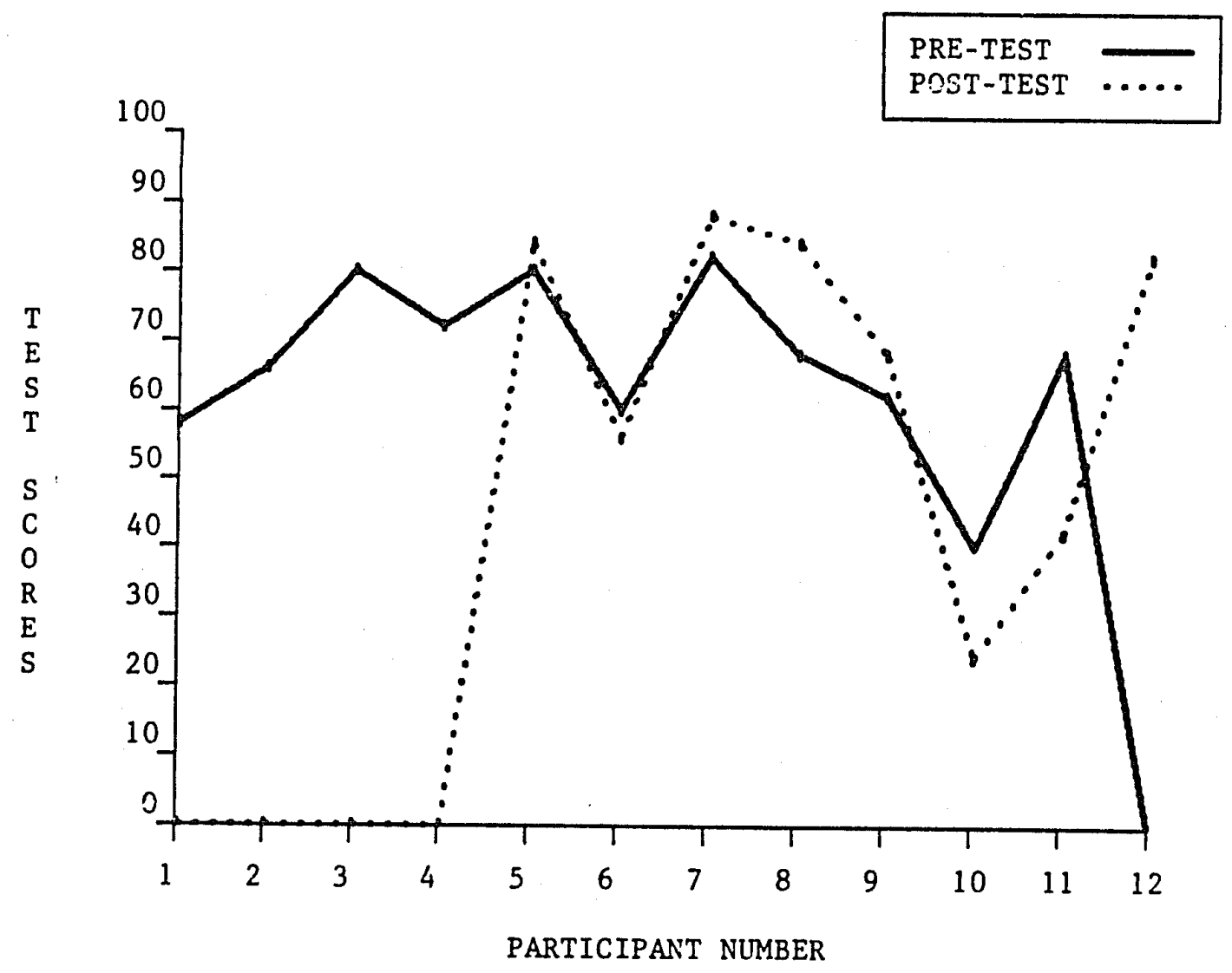

FIGURE 1. RAW SCORES OF PRE- AND POST-TESTS FOR SCHOOL AGE

PARTICIPANTS $(\mathrm{N}=12$ PRE-TEST; $\mathrm{N}=9$ POST-TEST) 


\section{PRE-TEST}

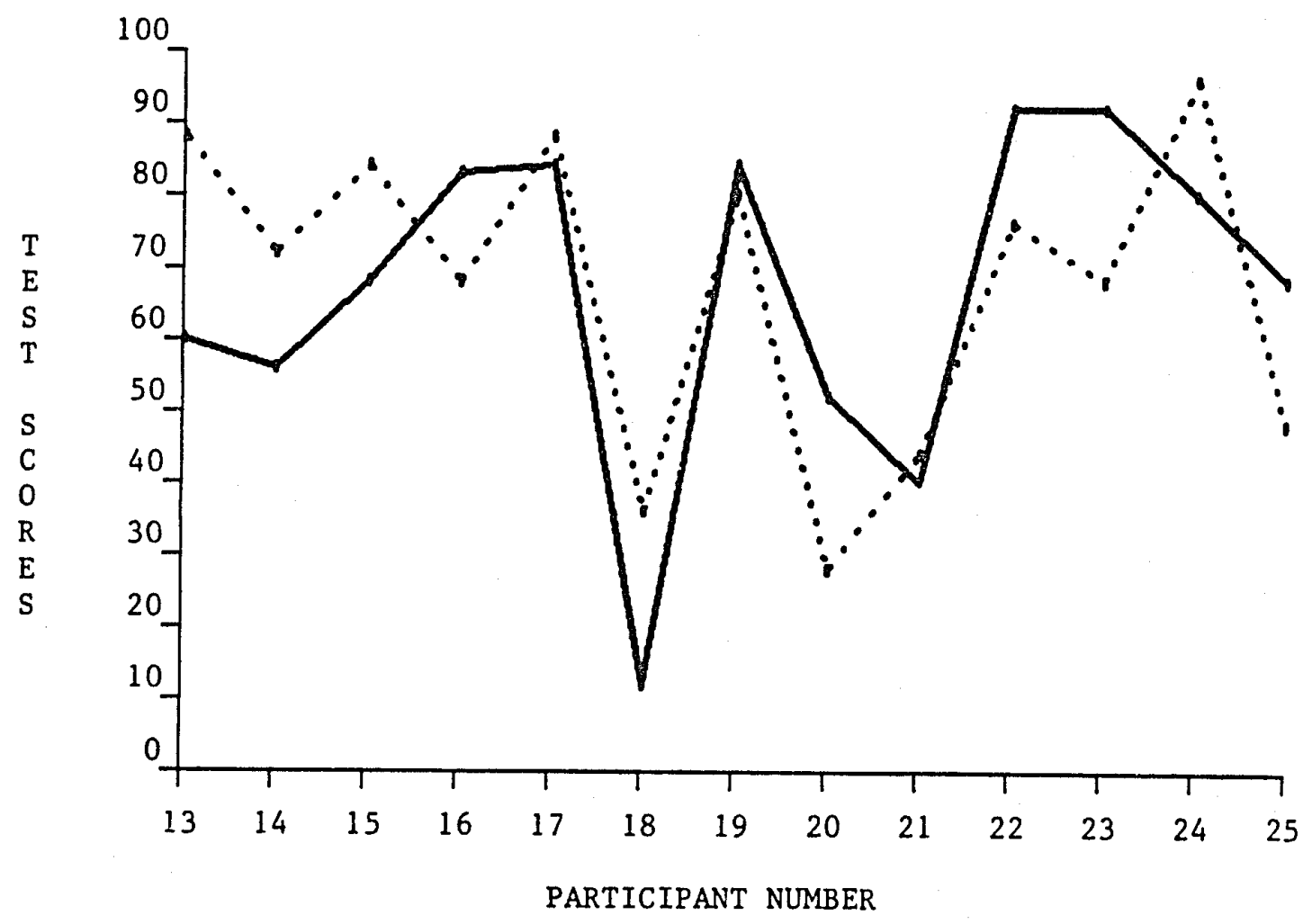

FIGURE 2. RAW SCORES OF PRE- AND POST-TESTS FOR ADULT AGE

PARTICIPANTS $(\mathrm{N}=13$ PRE-TEST AND POST-TEST $)$ 
REFERENCES

i. 
References

Branden, N. (1987). How to raise your self-esteem.

Toronto: Bantam Books, p. 110 .

Coopersmith, 5. (1987). SEI Self-esteem inventory.

Consulting Psychologist Press.

Cox, C. \& Wachs, J. (1985, December). Motivation:

Vehicle for public health nursing intervention. Public Health Nursing, $\underline{2}(4), 202-212$.

Fenner, K. (I979, February). Developing a conceptual

framework. Nursing Outlook, 27, 122-126.

Flick, L.H. (1986, March-April). Paths to adolescent parenthood: Implications for prevention. Public Health Reports, $101(2), 132-147$.

Giblin, P.T., Poland, M.L., \& Sachs, B. (1987). Effects of social supports on attitudes and health behaviors of pregnant adolescents. Journal of Adolescent Health Care, $8,273-279$.

Giblin, P.T., Poland, M.L., \& Ager, J.W. (1988). Clinical application of self-esteem and locus of control to adolescent health. Journal of Adolescent Health Care, $\underline{9}(1), 1-14$.

Gilberts, R. (1983, August). The evaluation of self-esteem. Family and Community Health, 6(2), 29-49. Held, L. (1981, winter). Self-esteem and social network of the young pregnant teenager. Adolescence, $\underline{X V I}(64), 905-912$. 
Horn, M.E. \& Rudolph, L.B. (1987, Fall). An investigation of verbal interaction, knowledge of sexual behavior and self-concept in adolescent mothers. Adolescence, XXII(87), 591-597. Joseph, L.S. (1980, March). Self care and the nursing process. Nursing Clinics of North America, $15(1), 131-143$.

Koniak-Griffin, D. (1988). The relationship between social support, self-esteem, and maternal-fetal attachment in adolescents. Research in Nursing and Health, 11, 269-278.

Lineberger, M. (1987, spring). Pregnant adolescents attending prenatal parent education classes: Self-concept, anxiety and depression levels. Adolescence, XXII(85), 179-192.

Marriner, A. (1986). Nursing theorists and their work, St. Louis: C. V. Mosby. Maslow, A. (1968). Toward a psychology of being. New Jersey: Van Nostrand.

Meisenhelder, J.B. (1985, February). Self-esteem: A closer look at clinical interventions. International Journal of Nursing Studies, 22(2), 127-135. Mercer, R. (1985, January). Teenage pregnancy as a community problem. Annual Review of Nursing Review, $\underline{3}(3), 7-76$. 
Mercer, R.T. (1979). Perspectives on adolescent

health care. Philadelphia: J.B. Lippincott.

Orem, D.E. (1985). Nursing: Concepts of practice.

New York: McGraw-Hill, 102-148.

Orr, D., Wilbrandt, M., Brach, C. Rauch, S., \&

Ingersoll, G. (1989, January). Reported sexual

behaviors and self-esteem among young adolescents.

American Journal of Disease in Children, 143(1), 86-90.

Pass, C.M. (1986, August). Psychological factors,

childbearing, and black female adolescents. Journal of

Pediatric Nursing, $1(4), 247-259$.

Patten, M.A. (1981, Winter). Self-concept and

self-esteem: Factors in adolescence. Adolescence,

$16(64), 765-778$.

Protinsky, H., Sporakowski, M. \& Atkins, P. (1982,

Spring). Identity formation: pregnant and non-pregnant adolescents. Adolescence, XVII(65), 73-80.

Reasoner, R. (1983, August). Enhancement of self-esteem

in children and adolescents. Family and

Community Health, $6(2), 54-55,63$.

Senate Office of Research. (1984, October). "Mom,

Dad.... I'm Pregnant: A special report on adolescent pregnancy." Joint Publications Office.

Streetman, L. (1987, Summer). Contrasts in the self-esteem of unwed teenage mothers. Adolescence, $\underline{X X I I}(86), 459-464$. 
Triola, M. (1983). Elementary statistics, (2nd ed.).

California: Benjamin/Cummings Publishing Co.

Vernon, M.I., Green, J.A., Frothingham, T.E. (1983,

November). Teenager pregnancy: A perspective study of

self-esteem and other sociodemographic factors.

Pediatrics, $12(5), 632-635$.

Wilson, H. \& Kneisl, C. (1983). Psychiatric nursing,

(2nd ed.). California: Addison-Wesley Publishing Co.

Wyatt, G.K. \& Omar, M.A. (1985, April).

Interventions useful to the public health nurse:

Improving health behaviors. Journal of Nursing

Education, $16(4), 168-170$.

Zuravin, S.J. (1988, January). Child treatment and

teenage first births: A relationship mediated by

chronic sociodemographic stress? American Journal of

Orthopsychiatry, 58(1), 91-103. 
APPENDIX A

Participant Consent Letter 
AGREEMENT to PARTICIPATE in RESEARCH at SAN JDSE STATE UNIVERSITY

Investigators: Joyce Brown, RN, PHN, Kim Smith, RN, PHN, and Alene Uchishiba, RN, PHN

Teen Pregnancy Prevention Program:

Your child is invited to participate in a research study that is investigating self-esteem in relationship to teenage pregnancy. The results of this study should further our understanding of the effects of public health nursing intervention on the self-esteen of pregnant and parenting teenagers.

I understand that:

1) my child will be asked to complete a pre-and post-test on self-esteem which will take 20 to 30 minutes.

2) the possible risk of this study is that the pre-and post-test nay elicit negative feelings about sensitive issues.

3) there are no direct benefits to my child.

4) the results from this study may be published, but any information from this study that can be identified with my child will remain confidential and will be disclosed only with my permission or as required by law.

5) ang questions about my child's participation in this study will be answered by Joyce Brown, Kim Smith, or Alene Uchishiba at 757-1061 or 899-4271. Conplaints, about the procedures may be presented to Sharon Hogan', graduate coordinator, at (408) 924-3134. "If there are questions about research-related rights of volunteers, direct them to Dr. Serena Stanford (Assoc. AVP Graduate Studies and Research) at (408) 924-2480.

6) my consent is given voluntarily without being coerced; my child mag refuse to participate in this study or in ang part of this study, and I may withdraw my consent at any time, without prejudice to my relations or my child's with S.J.S.U. and Monterey County Health Department.

7) I have received a copy of this consent form for my file. .

HAVING READ THE INFORMATION PROVIDED ABOVE, I HAVE MADE A DECISION WHETHER OR NOT MY CHILD MAY PARTICIPATE. MY SIGNATURE INDICATES THAT MY CHILD MAY PARTICIPATE AND IS WILLING TO PARTICIPATE. 
AGREEMENT to PARTICIPATE in RESEARCH at SAN JOSE STATE UNIVERSITY Investigators: Joyce Brown, RN, PHN, Kim Smith, RN, PHN, and
Alene Uchishiba, Ri, PHiN

Teen Pregnancy Prevention Progran:

I have been asked to participate in research study that is investigating self-esteem in relationship to teenage pregnancy. The results of this study should further our understanding of the effects of public health nursing intervention on the self-esteem of pregnant and parenting
teenagers.

I understand that

1) I will be asked to complete a pre- and post-test on selfesteem which will take 20 to 30 minutes.

2) the possible risk of this study is that the pre-and post-test may elicit negative feelings about sensitive

3) there are no direct benefits to me.

4) the results from this study may be published, but any information from this study that can be identified with me will remain confidential and will be disclosed only
with ony permission or as required by law.

5) any questions about my participation in this study will be answered by Joyce Brown, Kin Smith, or Alene Uchishiba at 757-1061 or 899-4271. Complaints about the procedures may be presented to Sharon Hogan, graduate coordinator, at (408) $924-3134$. If there are questions about research-
related rights of volunteers, direct them to Dr. Serena
Stanford (Assoc. AVP Graduate Studies and Research) (408) 924-2480.

6) my consent is given voluntarily without being coerced; I may refuse to participate in this study or in any part of this study, and I may withdraw my consent at any time, without prejudice to my relations with S.J.S.U. and Monterey County Health Department.

7) I have received a copy of this consent form for iny file.. I HAVE MADE A DECISION WHETHER OR NOT TO PARTICIPATE. MY SIGNATURE INDICATES THAT I HAVE READ THE INFORMATION PROVIDED ABOVE AND THAT I HAVE DECIDED TO PARTICIPATE. 
APPENDIX B

Introductory Letter 


\section{MONTEREY COUNTY}

DEPARTMENT OF HEALTH ROBERT J. MELTON. M.D., M.P.H.. Director

\section{PREVENTIVE MEDICINE}

MENTAL HEALTH

ENVIRONMENTAL HEALTH

ALCOHOL AND DRUG PROGRAMS

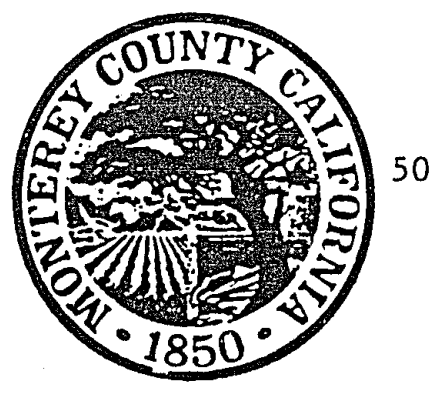

T1270 NATIVIDAD ROAD. SALINAS. CALIFORNIA 93906-3198 (408) 757.1061

1200 AGUAJITO ROAO. MONTEREY, CALIFOANIA 93940-409B

1180 EROADWAY, KING CITY, CALIFORNIA 93930 (408) 385.1291

Please Reply to adoRess Checked

Date:

Dear :

We are asking you to fill out this questionnaire to help us find out if your public health nurse visits are helping you feel better about yourself. The questionnalre will only take a few minutes to fill out, and you will be asked to complete one when the nurse makes her first visit and again when she makes her last visit.

You will be asked to sign a consent form to be a part of our program. Thank you for helping us with this information.

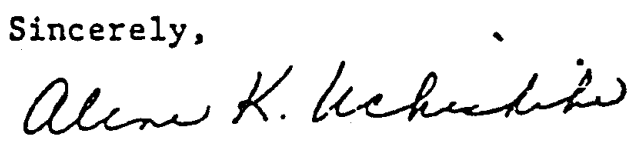

Alene K. Uchishiba, R.N., PHN Assistant Chief, PHNs

$\mathrm{AKU}: \mathrm{krf}$

$6 / 14-3$ 
APPENDIX C

Questionnaire for Demographic Information 
QUESTIONNAIRE FOR DEMOGRAPHIC INFORMATION

A. Sociodemographics

1. Age at entry

2. Grade completed

3. Ethnic/race

4. Marital status

single

married

living with partner

5. Zip Code (where lives)

6. Live with birth Eamily

yes

no

7. Seen by Social Worker (CPS, CPSP) yes

no

8. On Federal Program for Women, Infants and Children

yes

no

9. Employed

yes

no

10. Duration of pregnancy when pre-test given

first trimester second trimester third trimester post-partum

11. Duration of pregnancy when post-test given

first trimester second trimester third trimester post-partum 
B. Health History

1. History of chronic disease yes

no

2. History of substance abuse yes

no

3. History of other abuse yes

no

4. EDC

5. Gravida

6. Para

7. Abortion

C. Family History

1. Birth order oldest middle youngest

2. Was a sibling a teen parent? yes

no

3. Was mom a teen parent? yes

no 
APPENDIX D

Permission Letter for Use of Tool 
Wevre Trout

Oresing Departnient

Publishers Test Service

C.T.E. McGraw Hill

2500 garderi Rd.

Montei E;', CA 93940

SEsr irr. Trout,

This is to corifrim that the following students, Joyce Erown, Kim Smith, and Alerie Uchishiba are graduate students at San Jose State University. They ars plarining to use the Cooper Smith Self Esteem inventories in their tinesis work. on assessing self esteem of pregnant teenagers and teenage niothers and are antiorized to purchase the inventories from your company.

The are allowed to purchase the Cooper Smith Manual 1565278 for $\$ 6.50$; the $C-5$ School form $=1565378$ for $\$ 5.75$ for 25 ; the $C-S$ Adult Forrn $=1555.78$ for $\$ 3.75$ for 25 ; the $C-5$ school form scoring key $\$ 1565578$ for. ?.?3; and the C-5 adult form scoring key $\$ 1565678$ for $\$ 1.50$.

T.a:le you for any'Essistance you can provide these stucients. If you have n! a irses vou may contact me or Sinarnn Hogan. Graduate Coordinator at

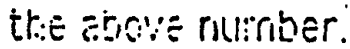

Singerely you:s,

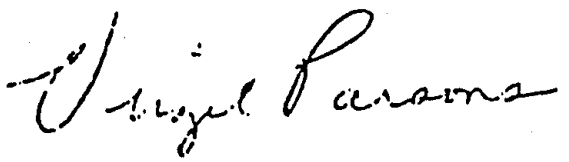

Viroil Parsons RN, DN!SC

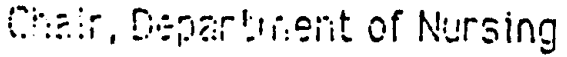
soid dos stoto irilyeretgy 
APPENDIX E

Coopersmith SEI 

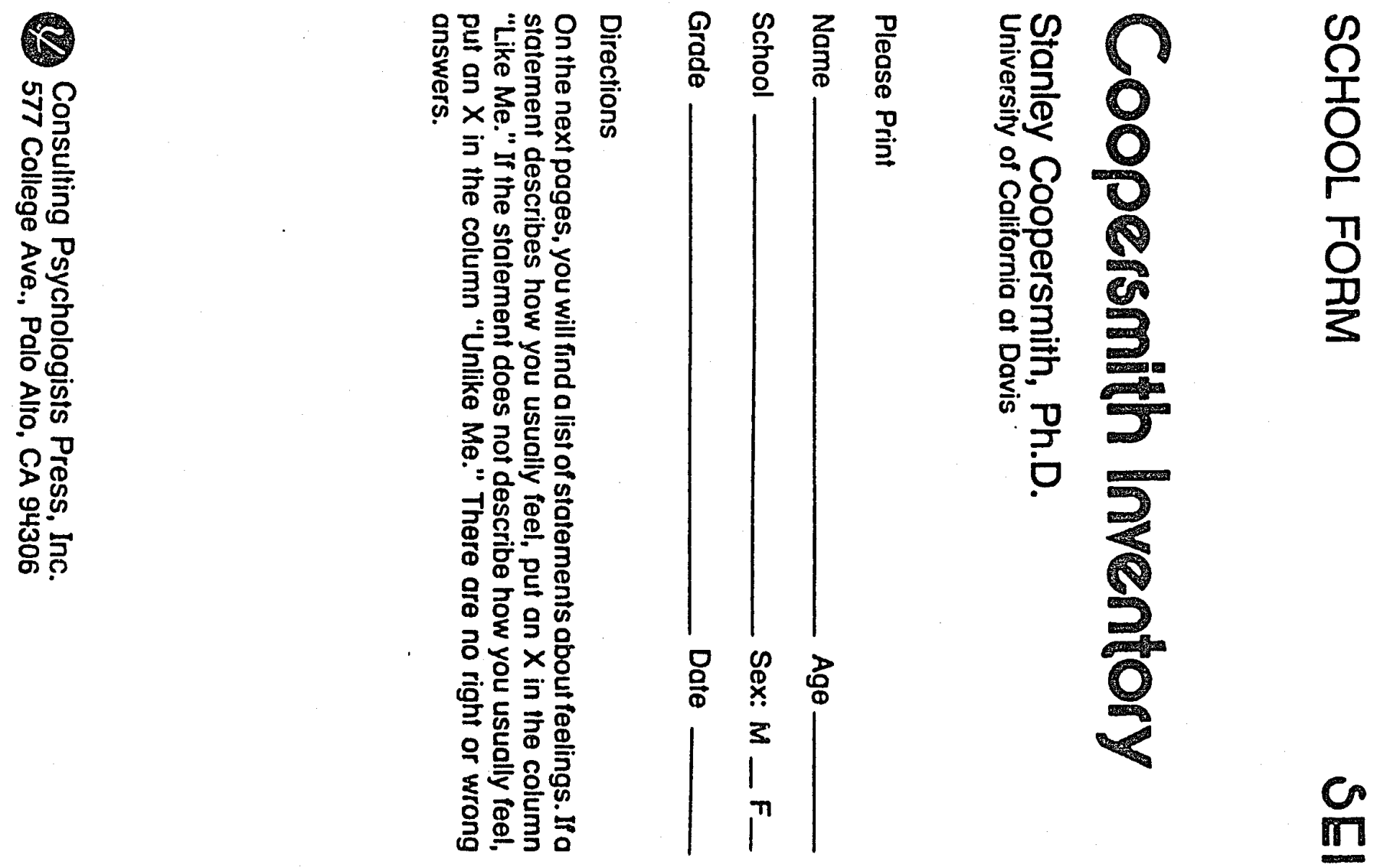


\section{Coopersmith Inventory}

\section{Stanley Coopersmith, Ph.D.}

University of California at Davis

Please Print

Name

Age

Institution

Sex: $M-F$

Occupation

Date

\section{Directions}

On the other side of this form, you will find a list of statements about feelings. If a statement describes how you usually feel, put an $X$ in the column "Like Me." If a statement does not describe how you usually feel, put an $X$ in the column "Unlike Me." There are no right or wrong answers. Begin at the top of the page and mark all 25 statements.

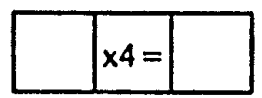

Consulting Psychologists Press, Inc.

577 College Ave., Palo Alto, CA 94306 
APPENDIX F

Monterey County Health Department Trap Form 
Acceptance of Pregnancy

A \& P of Pregnancy/Fetal G \& D

Emotional Factors

Family Relationships

Preparation for New Baby

Body Image/Sexuality

Nutrition

Dental Care/Hyglene

Drug/Substance Usage

AP Risk from Diseases/Environment

Common Discomforts

S/S of Complications

Infant Feeding/Breast Feeding

Labor and Dellvery

Breathing Exercisea

Expectations: Pr Perlod/Parenting

Hospltal Arrangements

Help at Home after Birth

Contraception

Community Resources

Socio-Economic

Mddical Appointments

ReceptIve to PHI

Literature GIven

See Other Check118t

R.V. Date

Type of Visit (NP, OV, HV, TC)

Recording Code: T - Taught/Informed

R - Referred

A - Assegsment Made

P - Progress Notes

\begin{tabular}{|l|l|l|l|l|l|l|l|l|l|l|l|}
\hline & & & & & & & & & & & \\
\hline
\end{tabular}




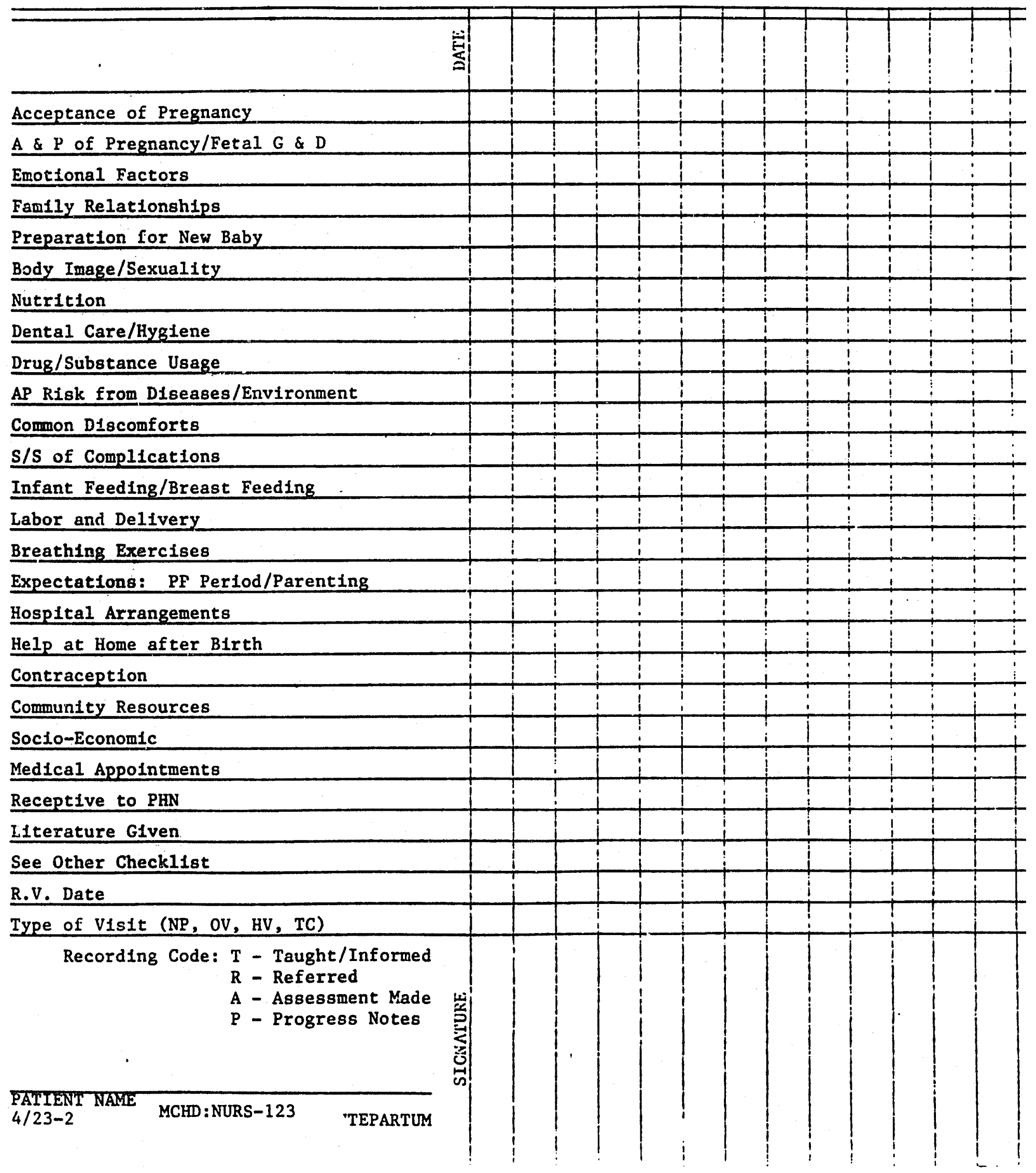


I. NURSING SERVICES AND TRAP FORMS

1. AP - Antepartum

a. Purpose:

1) To minimize PHN charting time and to provide a standardized guldeline for health teaching and supervision of antepartum ilients.

b. Procedure for completion of form (form following):

1) A.P. Checklist

a) Acceptance of Pregnancy - Assessment of where client stands regarding her pregnancy. The PHN should assess for high risk factors. Is pregnancy wanted or planned? Is client considering TAB or an adoption?

b) A \& P of Pregnancy - Anatomy and physiology of pregnancy, relate to: common discomforts, normal body changes related to fetal growth and development and labor and delivery, menses, ovalation, conceptional fertilization, 
sexuality in pregnancy, general hygiene and avoldance of douching. Include conception, birth control, effects of drugs and infection on developing embryo, weeks of gestation, quickening, lightning, cervical dilation, delivery, expulsion of placenta.

c) Emotional Factors - include mood changes, attitudes toward pregnancy, fears and concerns, partner's attitude, how well one communicates with her partner.

d) Family Relationships - Explore acceptance of her/his parents of pregnancy, and how supportive is their extended family. How will this baby alter this relationship?

e) Preparation for New Baby - Discuss how older children are being prepared for the arrival of a new baby. Topics of discussion might include: sibling rivalry, nesting-collecting clothing and equipment for the baby, and resources and referral information for care. 
f) Body Image/Sexual Counseling - Lack of desire to have sexual relations during lst trimester. Advise client that in 3rd trimester women become very sexually destrous and these changes are due to changes in hormonal levels. General acceptance of temporary physical changes.

8) Nutrition - Relate adequacy of diet to her needs and to those of developing baby. There may be specific Individual needs, such as, need for more iron, and calcium.

h) Dental Care/Hygiene - Include necd for dental evaluation and good dental hygiene.

1) Drug/Substance Usage - Include efferts of smoking/alcohol, unprescribed and prescribed medications including vitamins and $\mathrm{Fe}$, "reducing tablets", stool softners.

j) AP Risk Erom Disease/Environment Include VD, Herpes, chronic disease, e.g., asthma and diabetes. 
k) Common Disconforts - Include common discomforts and ways to alleviate them, e.8., muscle cramps and pa1n, suggest heat and massage, possibly increase $\mathrm{CA}$ in diet. Constipation, possibly suggest increase fluids, fruits, exercise.

1) $\mathrm{s} / \mathrm{s}$ of Complications - Blurring of vision, edema of hands and face, headaches, elevated temperature, pain on urination with decreased volume of urinary output, or vaginal bleeding. These need prompt medical attention.

m) Infant Feeding/Breast Feeding - Advice of community resources, e.g., La Leche League, C.E.I. Review all points for successful breastfeeding. Position, attitude, on demand, getting nipple and areola In Infant's mouth, alternating breast, hygiene, diet, adequate Intake of fluids, heat stimulates milk "let down", engorgement. Review A \& $P$ of lactation, expression of milk, use of pump or manual expression, storage of breast mile $\left(24^{\circ}\right.$ in refrigerator, 1 rorti in freezer). Major nutrition is 
recelyed in first 10 min. of nursing on each breast.

n) Labor and Delivery - Review s/s of Impending delivery, lightening, true vs false contractions, "pink show", passing of mucous, rupture of amnionic sac.

o) Breathing Exercises - Recỏmmended during three stages of labor. Relaxation and deep breathing, panting, pushing.

p) Expectations during PP Period - Include physical and emotional changes. Consider type of delivery and what to expect, e.g., C/Section; incision, drainage and healing. Vaginal delivery, Lochia, episiotomy. Breast engorgement. Discuss Postpartum depression, mood changes.

What are each partners expectations of oneself? Are the behavioral expectations of the infant age approprlate? 
q) Hospital arrangement - Registration, remind to take washed baby clothes and clothes for herself to take to hospital, plan out transportation, financial arrangements, length of hospital stay.

r) Help at Home after Birth - Encourage client to make plans to relate to needs for adequate rest.

s) Contraception - Discuss family planning methods, advise client" of all alternatives and effectiveness of each. Discuss reasons for practicing birth control, encourage discussion with partner. Advise regarding possible to become pregnant prior to lst P.P. period. Advise regarding breast feeding not a viable means of contraception.

t) Community Resources - Familiarize client with Health Department services and other community resources. When making a specific referral enter "p" on check Iist and not in progress notes.

u) Medica! Appointments - Stress importance 
of keeping appointments and on-going medical supervision.

v) Socio-Economic - Assess whether there are problems with insurance, food, clothing, housing, etc., refer to appropriate resources.

w) Receptive to PHN - Is patient receptive to PHN or not? If not enter a "P" on checklist and SOAP in progress notes. An " $A$ " means assessment wis made and reception was positive.

x) Literature Given - Check if Iiterature given.

y) See Other Checklist - If patient is also belng followed for other services, designate what other checklists were used. (H.C. = handlcapped, $S=$ SIDS, $\mathrm{CA} / \mathrm{N}=$ child abuse/neglect, T.B. = Tuberculosis.

2) R.V. Date - Revisit date.

aa) Type of Visit ( $\mathrm{NP}$, OV, HV, TC) - encer appropriate code. 


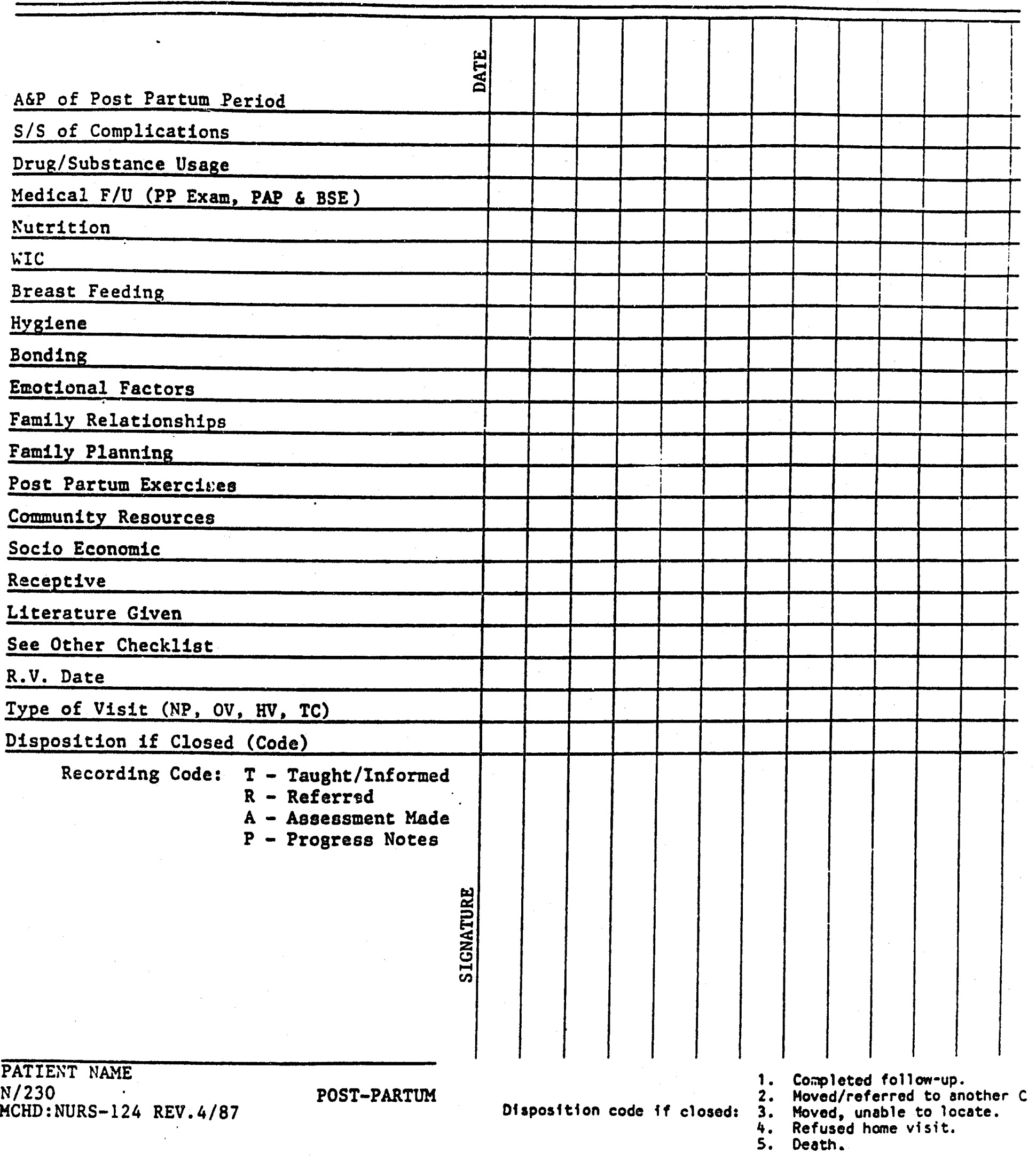




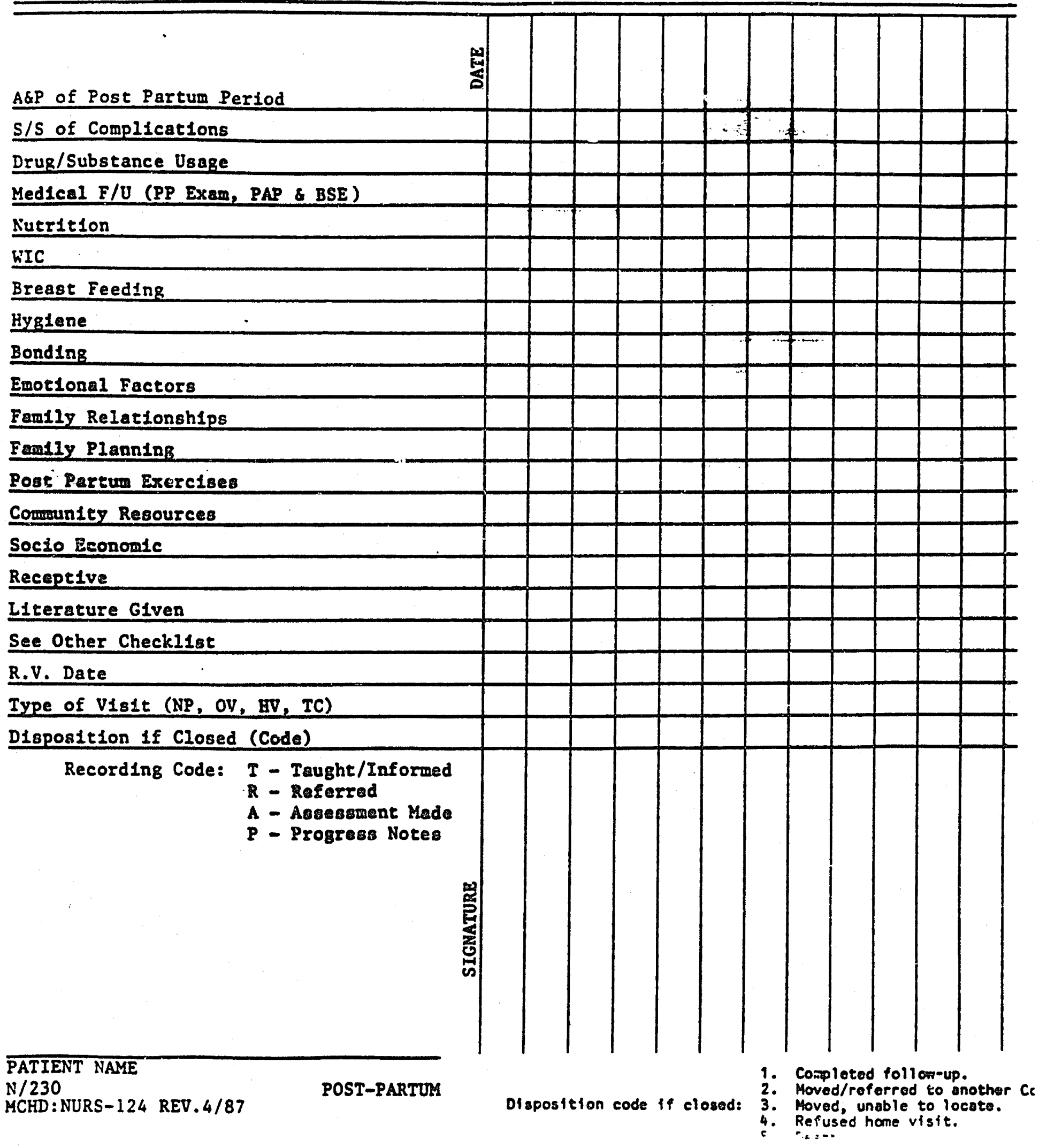


When a revisit is not planned, write $\theta$ In R.V. date line.

When client is to be transferred to a new area $\mathrm{PHN}$, date and * write "transferred" vertically. Enter new address under "address changes".

When unable to locate client, date and write in vertically. N.P.T.C. may be entered on checklist.

Telephone calls for appointments followed by N.P. visit is to be noted in progress notes as it is significant that cllent broke an established appointment.

\section{bb) Closed Disposteton Code - Enter appropriate code representing reason for closure.}

\section{2. $\quad \underline{P P}$ - Post Partum}

a. Purpose:

1) To minimize PHN charting and to provide a standardized guideline in the health teaching and supervision of post partum patients. (Post partum perlod $=$ Two months after parturition.) 
b. Procedure for completions of form (form following):

1) P.P. Teaching LIst

a) A\& P of post-partum pertod - Anasomy and physiology of post partum perfod. Relate to lactation, Involution, elfmination, resumption of sexual relations, rest, activity, vitamins and Iron, remind client that when breast feeding she may have ory vagina, therefore, recommend use of lubricant such as $K-Y$ jelly.

b) S/S of Complications - Blurring of vision, edema of hands and face, headaches, elevated temperature, pain or urination with decreased volume of urinary output, or vaginal bleeding. These need prompt medical attention.

c) Drug/Substance Abuse - Include taking of prescribed vitamins and fron, etc., effects of smoking, caffeine, alcohol and unprescribed drugs (illegal and over the courter). 
d) Medical F/U (PP Exam, PAP \& BSE) Stress importance of keeping appointments and on-going medical supervision, post partum exam, PAP \& BSE.

e) Nutrition - Evaluate eating habits. Assist in modifying diet as needed to meet normal nutritional réquirements.

f) WIC - Was teaching done about WIC and was a referral made?

g) Breast Feeding - Care of nipples, preparation of nipples: Advice of community resources, e.g., La Leche League, C.E.L.

h) Hyglene - Review peri-care, breast care, care of Inciston, sitz bath, use of heat lamp.

1) Bonding - Assess parent/child bonding. Review ways bonding occurs for both partners. Discuss significance of bonding. High risk for $\mathrm{CA} / \mathrm{N}$ if child. has no value to farents. 
j) Emotional Factors - Relate to hormonal changes. Be sensitive to prolonged feelings of depression and possible need for psychlatric counseling. When a woman has a st1llborn, aborts, or has delivered a handicapped child offer grief counseling.

k) Family Relationships $i$ - Assess relationships. Emphasize necessity of communication to positive relationships. Baby does not solve problemś; sometimes complicates existing relationships. Review adjustment areas on parenting. Stress the Importance of a stable parent/child, parent/parent relationship.

1) Family Planning - Using family planning kit, discuss, and demonstrate as approprlate, use of various contraceptive methods.

m) Post Partum Exercises - Use suggested pamphlets and demonstration to review muscle toning/strengthening. Review and demonstzase Kagel exercises and all others as per M.D. 
n) Community Resources - Familiarize client with Health Department services and other communtey resources. When making a specific referral enter " $P$ " on check list and note in progress notes.

o) Socio-Economic - Assess whether there are problems with insurance, food, clothing, housing, etc., refer to approprlate resources.

p) Receptive -. Is cllent receptive to PHN or not? If not enter a "P" In checklist and SOAP in progress notes. Enter an "A" If assessment made and receptirn was positive.

q) Literature Given - Check if given.

r) See Other Checklist - If client is also being followed for other services, designate what other checklists were used. (H.C. = handicapped, $S=$ SIDS, $C A / N=$ child abuse/neglect, T.B. Tuberculosis, Inf. (Infant.)

s) R.V. Date - Revisit date. 


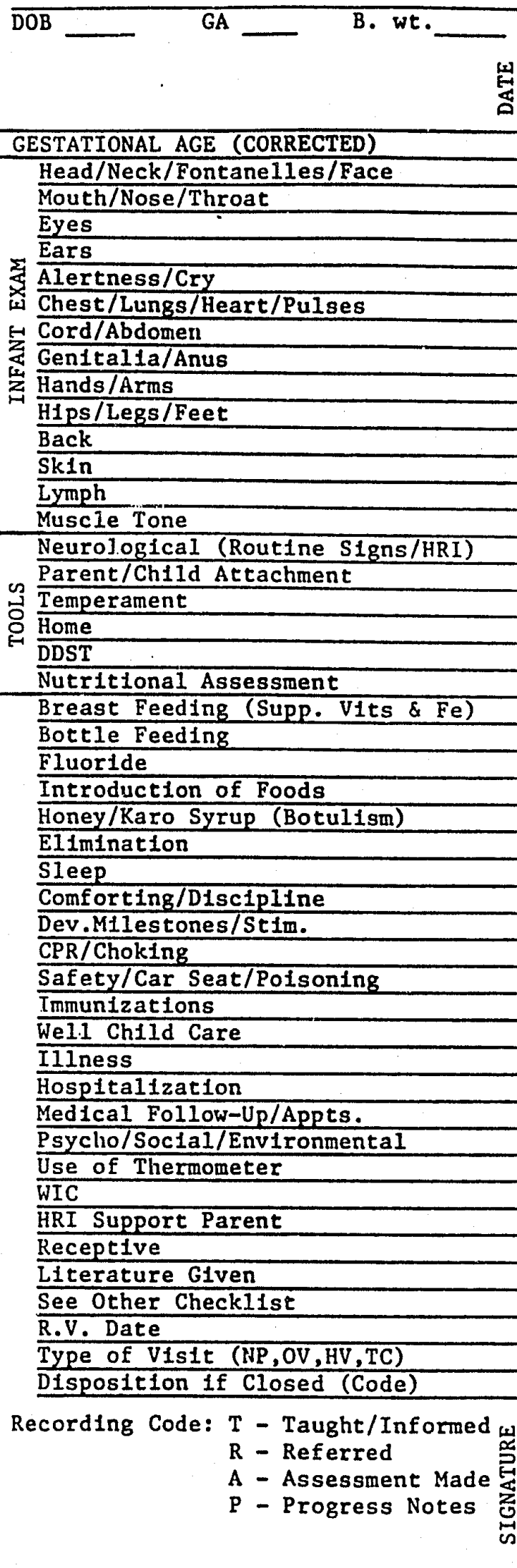

Patient Name

N/ 166

MCHD : NURS -17
INFANT/HRI
Apgar __ Type of delivery

幽

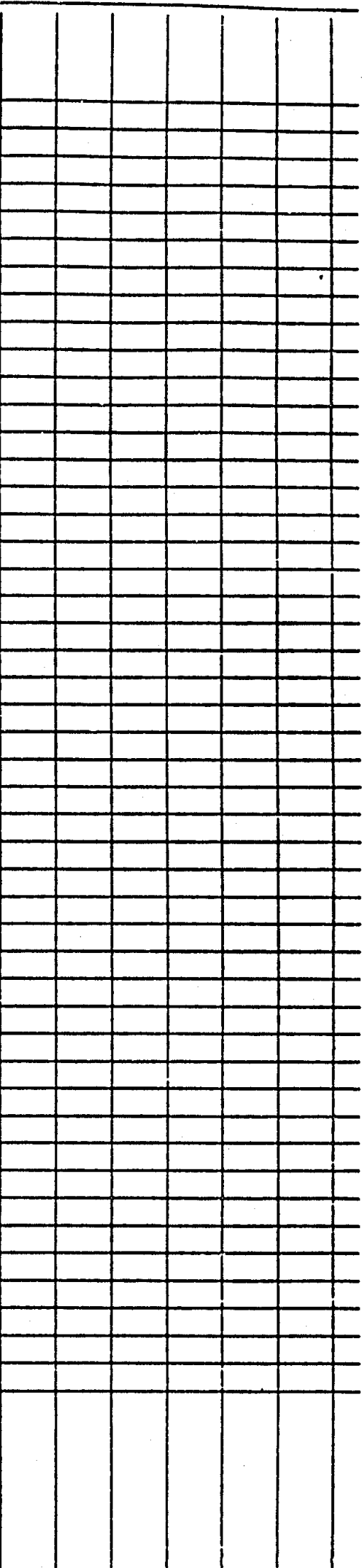

1. Completed follow-up.

2. Moved/referred to another Co.

Disposition code if closed:3. Moved, unabie to locate.

4. Refused home visit.

5. Deach. 


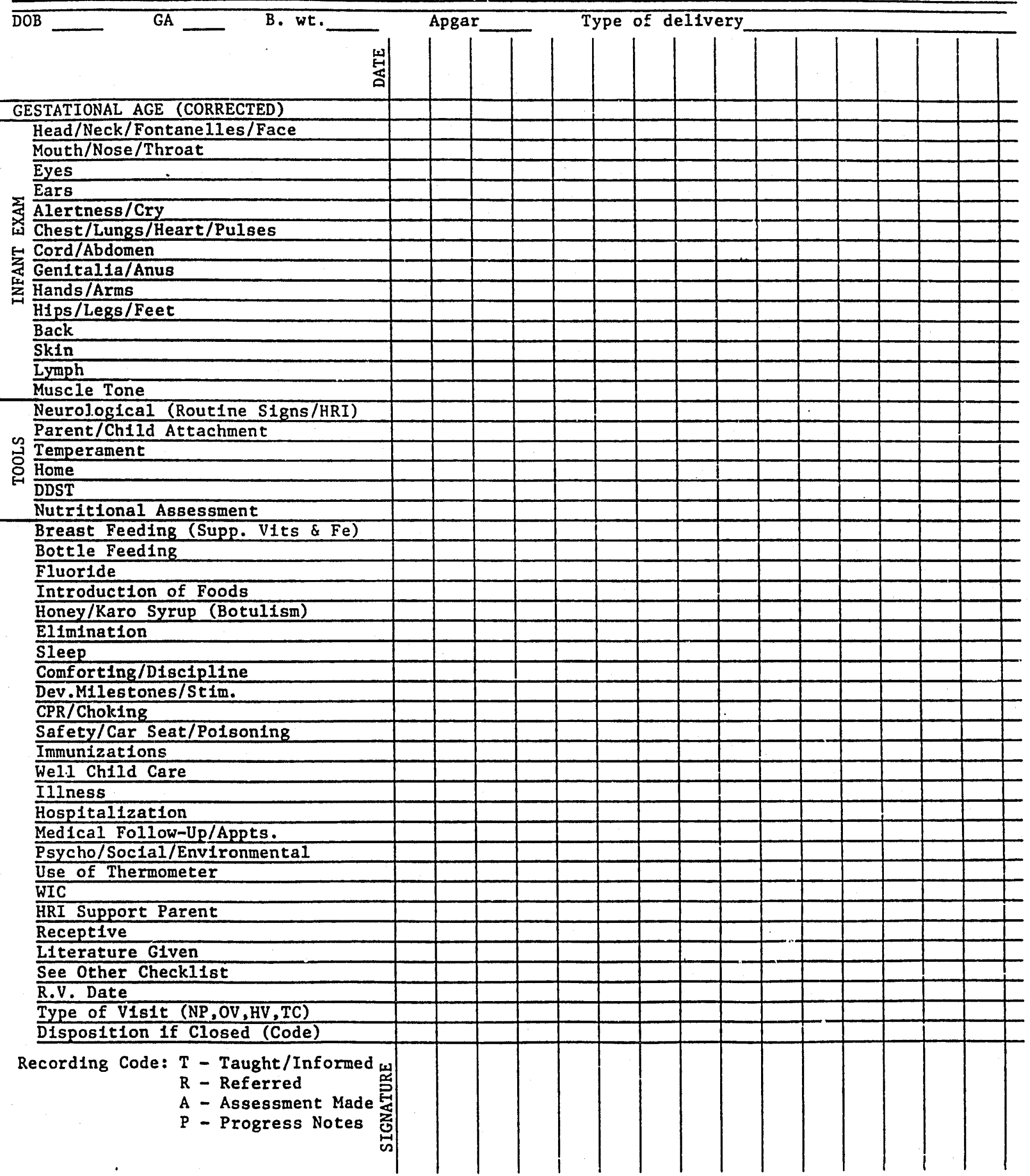

1. Completed follow-up.

Patlent Name

N/166

MCHD : NURS- 17
INFAN'- 'HRI
2. Moved/referred to another Co. Disposition code if closed:3. Moved, unable to locate.

4. Refused hame visit.

5. Deach. 
r) Type of Visit (N.P., O.V., H.V., T.C.) Enter appropriate code.

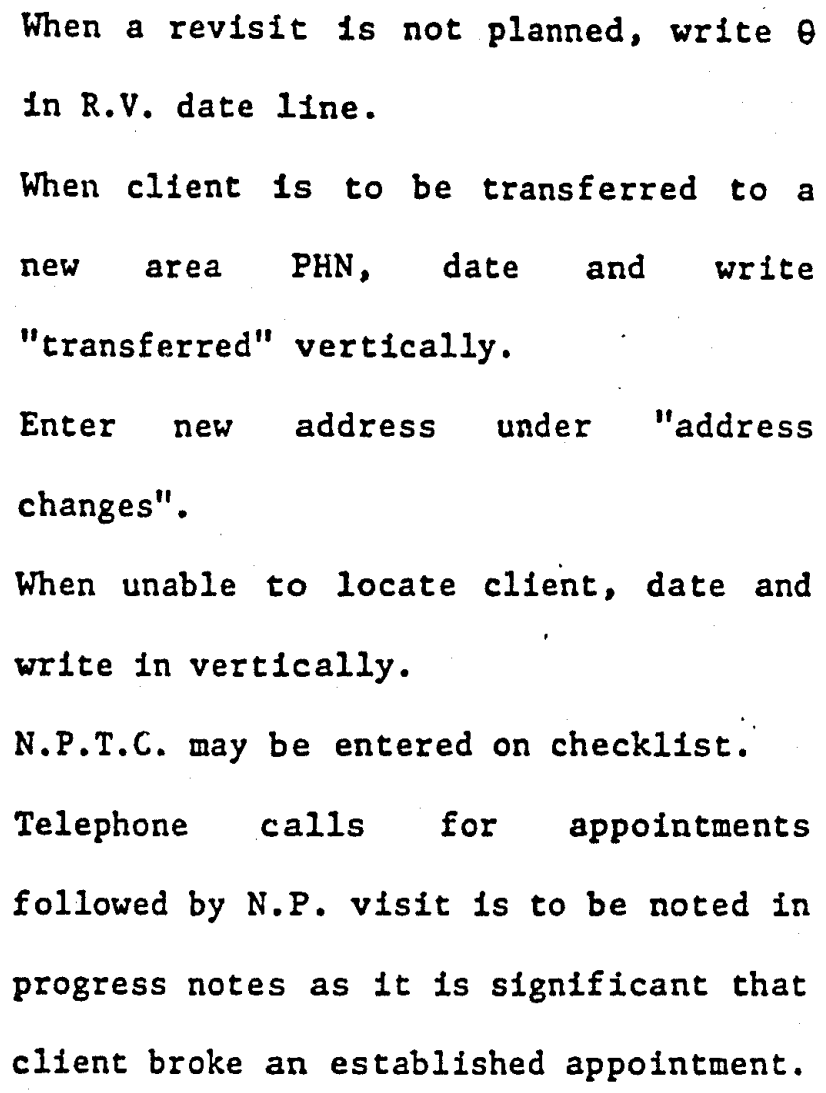

u) Disposition if Closed

3. Infant and High Risk Infant

a. Purpose:

1) To minimize PHN charting time and to provide a standardized guideline for health teaching. and supervision of infants/HRI. 
b. Procedure for completion of form (form following):

Introduction: This form is to be used for all infants open to service; HRI's 1ncluded. If the infant has congenital abnormalities which necessitate intervention use the Handicapped TRAP Form with the Infant TRAP Sheet. Do not fill in duplicate 1tems.

1) Fill in spaces on top of form with appropriate data.

2) Infant exam - The Infant exam shall be done on all Infants whenever possible. Parts of the exam may be done on multiple visits or on any given visit. Refer to Alexander and Brown Pediatric and Physical Diagnosis for Nurses, and Bates, $A$ Guide to Physical Examination.

a) Gestational Age (Corrected) - Calculate and record the corrected gestational age for the infant for each visit.

b) Head/Neck/Fontanelles/Face - Assess head for contour, symmetry, fontanelles, markings, cephalohematoma. Assess neck for torticollis, markings, masses. 
Discuss fontanelles and need for supporting neck and head during early infancy. Check expression and symmetry of face.

c) Mouth/Nose/Throat - Assess miuth for abnormal markings, thrush, teeth, soft palate. Assess nose for rontour, discharge. Assess thrioat for any unusual markings or swelling. Use tongue blade and flash light to check for abnormalities. Advise "parents to not use commercfal nose drops.

d) Eyes - Assess eyes for symmetry, discharge, excessive tearing, pupil response, or any abnormal markings/findings. Use penlight for assessment.

e) Ears - Assess ears for symmetry, discharge, position, and abnormalities. Advise parents not to use Q-tips or bobbie pins to clean ears.

f) Alertness/Cry - Assess infants responsiveness and character of cry. 
Discuss infants cry as the main means of communication und that appropriate parent responsiveness is extremely 1mportant, e.g., parents need to learn to differentiate.

8) Chest/Lungs/Heart/Pulses - Assess contour of chest. Observe, palpate, auscultate for quality of oreath sounds, respiratory rate, effort, symetry. Check nipples and breast tissue, auxillary nodes. Observe for pallor, cyanosis or diaphorests. Auscultate cardiac sounds. Check femoral and brachial pulses for evenness and quality. Palpace clavicles and foserve for full range of motion of the arms to make sure clavicular fracture does not exist.

h) Cord/Abdomen - Assess abdomen for distention, masses, organ enlargement, pain. Cord should be assessed for absence of infection or hernia. Give cord care instructions. Advise use of alcohol, keeping area dry, and position of diaper to kep moisture away frum cord area. 
1) Genitalia

(1) Male - Observe and palpate organs; check and palpate for testes, hernias, hydrocele, hypospadias. Advise not to force back foreskin of penis.

(a) Circumcision - Assess penis and advise regarding care.
Each hospital has its own
procedure. Some ise plastic
rims, others recommend
vaseline gauze. Encourage
contact with hospital for
specific instructions.
Otherwise encourage keeping
area clean and to watch for
bleeding or unusual swelling.

(2) Female - Check clitoris, urethral orifice; check for vaginal tags, adhesions; any discharge (odor, color, amount). Instruct regarding smegma and spotting as normal for the female infant. 
(3) Anus - Chook structure for fissure or tags.

j) Hands/Arms - Assess for abnormal findings, webbing, simian creases, extra digits.

k) Hips/Legs/Feet - Assess for abnormal findings, hip click, symietry, contour, adduction, and abduction. Check the symmetry of posterfor gluted folds. Check for extra digits. :

1) Back - Assess symmetry, contour and spinal column for dimples and tufts of hair.

m) Skin - Assess for dryness, rashes, lesions, hemangioma. Evaluate and discuss mongolian/mediterrian spots, cafe-au-lait spots (more than six is of concern). Teach regarding color, turgor, texture, lestons, normal/abnormal findings. Advise to not use cornstarch. Encourage moderation when using lotions, creams and powiders and other perfumed products. 
n) Lymph System - Evaiuate for any lymphadenopathy. (enlargement, warmth, tenderness, redness). Inspect and palpate nodes in accessible areas of head and neck area, axtllary area, arm, and inguinal areas.

o) Muscle Tone - Assess head lag, strength and muscle tone, graspi. Assess if flaccid, rigid, and hypotonic. In fallure to thrive, check for hypotonia. Discuss stimulation and development of muscle tone.

3) Tools

a) Neurological Assessment - See reverse side of tool for Instructions. A more complete guide and explanation is avallable in each nurses HRI folder. This tool should be used on premies under 1500 grams, infants with intraventricular hemorrhage, anoxia, neuro deficits, or infants who are at risk for cerebral palsy, CMV or Down's Syndrome. 
On routine infants use this line also even if tool is not used.

Assess bastc reflexes: moro, tonic neck, stepping, sucking, roating, and grasp. Check facial symmetry, L.O.C., alertness.

b) Parent/Child Attachmenti - See the reverse side of this tool for 1nstructions. This tool may be used on any child and parent. $A n^{\circ}$ assessment should be done Initially and then prn.

c) Temperament Assessment - See the reverse side of this tool for instructions. This is an optional assessment/teaching tool to use when parents do not understand the infants behaviors.

d) Caldwell Homes Assessment - See the reverse side of this tool for Instructions. A more detalled Instruction is avallable in each nurses HRI folder. This tool may be used on any child. The recommended frequercy for HRI is 6 month and 12 menths. 
e) DDST - Development screening is to be done on those infants who were compromised at bitch, and on those suspected of delays. Usual periodicity: 4, 6, 9, and 12 months (chronological age), but may vary according to need. A good assessment tool, especially in cases of $\mathrm{CA} / \mathrm{N}$, failure to thrive infants and parents with unrealistic expectations or with questionable parenting skilis.

f) Nutritional Assessment - For complete Instructions see the instructions in the Program GAIN packet given to each PHN. Brief instructions are also written on the back of this tool.

\section{4) Teaching List}

a) Breast Feeding (Supp. Vits. \& Iron) Assess quality of breast feeding; how often and how long infant remains on breast. Observe when quality questionable, as problem may be engorgement, lack of full grasp of nipple, inverted nipples, position, 
stress. Discuss need for supplemental vitamins ( $400 \mathrm{IU}$ of $\mathrm{D}$ ) and Iron ( $1 \mathrm{mg}$ per $\mathrm{kg}$ ).

b) Bottle Feeding - Assess feeding pattern, amount, type of milk/formula, position. Discuss demand feeding. Limit formula to $32 \mathrm{oz} . / 24 \mathrm{hr}$. period. Do not add honey, karo, or any other type of sugar to formula.

Hold child when bottle feeding. Discourage bottle propping to avold ear Infections, choking.

Do not put bottles in microwave. Heating can destroy vitamins and can cause severe burns. Bottles may explode due to the bulldup of steam from microwaving.

Discuss necessity for $F e$ enriched formula or supplement.

c) Fluoride - Encourage obtaining Rx from PMD. 
d) Introduction of Foods - Using WIC food Introduction guidelines, instruct regarding cautious introduction of solids. Discuss signs and symptoms of possible allergles to foods. Discuss. caloric requirements for normal growth. Discuss the need to not salt or sweeten foods or liquids. Discuss need for meal time to be a pleasant exṕerience. Food must not be used for rewards or punishments. See CHNC protocol for nutrition.

e) Honey and Karo Syrup - Caution against use of honey and karo syrup in formula, pacifier, etc., because of the risks of Infant Botulism.

f) Elimination - Assess and teach regarding normal and abnormal feces and urinary patterns. See CHNC protocol for diarrhea and constipation.

8) Sleep - See attached N-CAST sleep pattern scale. 
h) Comforting/Discipline - Assess and discuss interaction, bonding, setting age appropriate limits, rewards and parental gratification/expectations. Assess mother/father response to infant cry for needs to be met. Encourage being responsive to infant's cries. Advise parents that infants cannot be spoiled up to six months of age.

Meal time as a pleasant experience. Food should not be used for reward and punishment.

Caution against using food and meal time as a battle ground.

1) Dev. Milestones/Stim - Discuss need for parental stimulation of infant for developmental progress, 1.e., talking to infant, holding, stroking, age appropriate Infant stimulation and exercise. Use "Infant Care" pamphlet as a guide.

j) CPR/Choking - Use current American Heart Association guidelines to review basic 
Instructions for infant/child $C P R$ and Infant/child choking. Refer family to appropriate class for certification.

k) Safety/Car Seat/Poisoning - Safety teaching and accident prevention according to developmental age. Include not leaving alone on couch or in tub. Discuss fire hazaras, and small objects which may cause choking. Use "Infant Care" pamphlet as a gulde: Advise to put dangerous objects out of reach of Infant.

Discuss parental responsibility for supervision of child.

Discuss ipecac as a household 1tem to be used in emergency.

Stress and encourage car seat rental/purchase and use. Refer to avallable resources. Give handout as appropriate.

1) Immunizitions - Advise regarding regular schedule for I.Z.'s, importance and where I.Z.'s may be obtained. Use 
agency hand-out to enforce schedule.

m) Well Child Care - Advise of need and importance of well child care and where care may be obtalned.

The following categories are eligible for EPSDT/CHDP assistance:

(1) Medi-Cal recipients to age 21 years.

(2) School enterers who are $200 \%$ of poverty level - Kindergarten and first grade.

(3) Infants 0 - 13 months who are $200 \%$ of poverty level.

(4) Head Start attendees.

(5) State pre-school children.

If the child does not have a primary care provider, three providers of care will be offered. 
n) Illness - Discuss $\mathrm{S} / \mathrm{S}$ of 1llness, when to call the doctor. Discuss local resources and plans for sick care follow-up.

o) Hospitalization - Has the Infant been hospitalized and why. Chart "P" and SOAP if appropriate.

p) Medical Follow-Up/Appointments - This area of assessment should be done on all infants. It should Includé compliance with all medical appointments, medical treatments and or medications being given per doctor's orders.

q) Psycho-Socio-Environmental Status: Involve assessment of the following:

Psycho-social: Emotional environment, mother's physical and emotional feelings of delivery and post partum experfence, family unity, coping abilities, stress, respite, support systems, grievings, employment, Immigration status, family dysfunction, conflict, violence, inadequate parenting skills, mental 
health 1.e. depression, anxievy, suicidal, homicidal, psychotic thinking. Mother's progress notes should show mother's status, but a note on the infant sheet may indicate "see mother's note."

r) Use of Thermometer - Demonstrate how to take temperature. Refer to "Infant Care" pamphlet as a guide.

s) WIC - Advise regarding WIC "program and refer when appropriate. Use handout.

t) HRI Support Parent - This area should involve telling HRI clients about the avallability of support parents and any referrals requested.

u) Receptive - If client is not receptive to PHN enter a "P" and SOAP. Enter an " $A$ " If assessment indicates a positive reception.

v) Literature Given - Check if given.

w) See other Checkiist - If client is also being zollowed for other services, 